\title{
Painful Neuron-Microglia Interactions in the Trigeminal Sensory System
}

\author{
Alexander J. Davies, Yong Ho Kim and Seog Bae Oh*
}

\begin{abstract}
National Research Laboratory for Pain, Dental Research Institute and Department of Physiology, School of Dentistry, Seoul National University, Seoul 110-749, Republic of Korea
\end{abstract}

\begin{abstract}
The trigeminal sensory system is unique in its innervation of structures specific to the orofacial area. Nociceptive trigeminal afferents are known to synapse with second-order neurons in the trigeminal subnucleus caudalis (Sp5C) in the brain stem. The activity of neurons within the $\mathrm{Sp5C}$ is responsible for the relay of nociceptive signals to higher brain centers. Recent evidence suggests that central sensitization may be fundamental to many trigeminal-specific painful neuropathies, including trigeminal neuralgia and migraine.
\end{abstract}

Glia within the Sp5C are emerging as prime suspects in trigeminal central sensitization. In particular, microglial activation has been implicated in the development of neuropathic pain. It is possible that activated microglia release factors that alter the activity of second-order neurons or the synaptic activity of peripheral terminals within the Sp5C.

\begin{abstract}
Microglial activation has been characterized by changes in morphology, expression of membrane receptors and ion channels, as well as alterations to cytokine and chemokine release. In addition, microglia have been studied in brain slice and dissociated culture where activation is characterized by changes to $\mathrm{P} 2 \mathrm{X}$ receptor and potassium channel membrane currents. However, little is known about resting and activated microglial membrane properties in the Sp5C and, furthermore, how these properties are affected following trigeminal nerve injury. This review summarizes the anatomical and pathophysiological importance of the $\mathrm{Sp} 5 \mathrm{C}$ and focuses on recent studies on neurons and microglia in the trigeminal sensory system. The final part of the review aims to link important aspects of microglial membrane physiology with their potential role in chronic trigeminal pain conditions.
\end{abstract}

Keywords: Neuropathic pain, migraine, subnucleus caudalis, medullary dorsal horn, nerve injury, astrocyte, C-fiber, potassium channels, $\mathrm{P} 2 \mathrm{X}$ receptor.

\section{INTRODUCTION}

The trigeminal sensory system represents a distinct and complex functional unit, with its own well characterized nociceptive and modulatory pathways [1]. A range of severe facial pain syndromes, with varying aetiologies, are associated with trigeminal neuropathy [2]. Pain associated with nociceptor activation within structures specific to the orofacial area, such as the tooth pulp [3] and cornea [4], as well as the cranial dura [5], do not have clinical correlates in the spinal somatosensory system [6]. As such, the treatment regime for trigeminal-related pains may differ from that of spinal neuropathic pain.

Guidelines for the pharmacological treatment of neuropathic pain include tricyclic antidepressants, opioid analgesics and gabapentin, either alone or in combination; yet there is still clearly an unmet clinical need [7]. Recent success with the N-type calcium channel blocker, Ziconotide, has not escaped caveats associated with a narrow therapeutic window and the need for intrathecal injection [8]. These treatment strategies are in contrast to those employed for

\footnotetext{
*Address correspondence to this author at the National Research Laboratory, Department of Physiology, School of Dentistry, Seoul National University, 28-2 Yeongeon-Dong Chongno-Ku Seoul 110-749, Republic of Korea; Tel.: (82) 2-740-8656; Fax: (82) 2-762-5107;

E-mail: brainres@plaza.snu.ac.kr
}

trigeminal-related pain, such as migraine [9], where toxicity issues prevents their use in the head or facial area.

Anti-convulsants, such as carbamazepine, are often the primary medication used to treat chronic trigeminal neuralgia [10]; in more severe cases invasive procedures may be considered. Deep brain stimulation is one alternative for drugrefractory craniofacial pain syndromes [11]. Ultimately, surgery is an inevitable last resort for intractable trigeminal pain [10]. The rationale for the majority of available medications is to target and reduce neuronal activity directly. However, the glial cell population represents an untapped pool of possible pharmacological targets that, as we shall see, may prove more fruitful in the search for effective trigeminal neuropathic pain therapies.

It has become clear that two types of glial cell of the central nervous system (CNS) - microglia and astrocytes - play a pivotal role in the mechanisms of chronic pain, both at the spinal and trigeminal level. This review aims to incorporate these recent ideas with the latest findings in both central and peripheral trigeminal systems, with particular emphasis on the roles that microglia may play in the mechanisms of painful trigeminal neuropathies.

We begin by briefly introducing the basic anatomy of the trigeminal system and provide the rationale for studying trigeminal, as opposed to spinal, mechanisms in terms of nociceptive signaling. The review will focus more closely on the mechanisms of microglial activation, which occur soon after 
trigeminal nerve injury. It will also highlight the intrinsic properties of microglia in the various reported activation states. Finally, we will reflect on the implications of the latest findings in microglial activation properties.

\section{TRIGEMINAL NEUROANATOMY}

The trigeminal sensory system is responsible for relaying sensory information bilaterally from oral, facial and cranial regions to the CNS via three main branches of the trigeminal nerve: opthalmic, maxillary and mandibular [12]. The majority of trigeminal afferents are pseudounipolar with cell bodies lying in semilunar ganglion, with the exception of proprioceptive afferents whose cell bodies lie in the mesencephalic nucleus of the trigeminal nerve. Within the CNS there is a modal and somatotopic distribution of trigeminal primary afferents fibers between the various brain stem nuclei [13-15]. The majority of large diameter afferents are generally thought to synapse with neurons in the principal sensory nucleus, and small diameter fibers instead descend in the spinal tract to synapse with neurons in the large spinal nucleus of the trigeminal nerve (Sp5) [16-18].

The Sp5 has been subdivided into three parts based on cytoarchitectural differences observed in rabbit, monkey and human species [19]. From rostral to caudal these subnuclei are: oralis $(\mathrm{Sp} 5 \mathrm{O})$, interpolaris $(\mathrm{Sp} 5 \mathrm{I})$ and caudalis $(\mathrm{Sp} 5 \mathrm{C}$; also abbreviated ' $V c$ '). Of these three subnuclei, the Sp5C has been seen as contiguous with the spinal dorsal horn, lending the term 'medullary dorsal horn' [1]. The Sp5C has itself been subdivided into the layers zonalis marginalis, substantia gelatinosa, and magnocellularis, that roughly correspond to lamina I, lamina II, and lamina III-V of Rexed [20], respectively, yet are anatomically distinct from the spinal cord [17].

\section{TRIGEMINAL AND SPINAL PRIMARY AFFER- ENT SIGNALLING}

\subsection{Similarities and Differences}

Since the gate control theory of Melzack and Wall was proposed in 1965, the spinal and medullary dorsal horns have remained an area of intense research into the processing of incoming nociceptive signaling from the periphery to the CNS [21]. Nociceptive primary afferents synapse in the superficial layers of the spinal dorsal horn [22]. Thinlymyelinated $\mathrm{A} \delta$-fibers and unmyelinated $\mathrm{C}$-fiber afferents of the trigeminal nerve have also been shown to innervate the superficial layers of the Sp5C [18, 23, 24]. Importantly, the $\mathrm{Sp} 5 \mathrm{C}$ has received concurrent research into nociceptive processing based on many well-documented differences with the spinal sensory system $[1,6]$.

\subsection{Trigeminal Nociceptor Specificity}

Interest in the pain specificity of trigeminal sensory signaling intensified when it was realized chronic facial pain known as 'trigeminal neuralgia' could be treated by the surgical transection of the spinal tract of the trigeminal nerve [25]; the anatomical separation of high-threshold nociceptive fibers to this region meant that low-threshold mechanosensitive fibers remained intact [26] and thus patients retained relatively normal facial mechanosensation.

Unmyelinated C-fiber primary afferents can be separated into two broad categories: those containing neuropeptides
(peptidergic/IB4-negative) and those with immunoreactivity for the plant lectin isolectin B4 (non-peptidergic/IB4positive) [27]. In contrast to the spinal system, trigeminal afferents appear to show wider distribution across the medullary dorsal horn [6]. Heavy immunoreactivity for the neuropeptides substance $\mathrm{P}$ and calcitonin gene-related peptide (CGRP) occurs throughout the Sp5C and continues rostral to near the border with the subnucleus interpolaris [18], also known as the 'Vi/Vc transition zone' (Sp5I/Sp5C boundary) [15]. Immunoreactivity for IB4 can be seen to overlap that of substance $\mathrm{P}$ and CGRP in the most caudal part of the Sp5C but is lacking at the boundary with the Sp5I [24]. At the ultra-structural level, CGRP-containing afferent terminals appear most dense at the outer border of the Sp5C lamina II, with less CGRP fibers penetrating the inner lamina II [28]. A proportion of IB4-positive trigeminal ganglia neurons have been reported to contain CGRP, and vice versa [23]. This suggests that unmyelinated trigeminal afferents display a divergent anatomical distribution, yet at the same time includes a subset of fibers with an overlapping neurochemical phenotype.

The response of primary afferents to nerve injury also appears to differ between spinal and trigeminal systems. Less ectopic spontaneous activity was recorded in trigeminal infraorbital nerve (ION) after nerve transection compared with the same procedure in the sciatic nerve, with C-fibers, in particular, showing the greatest contrast [29]. Sprouting of sympathetic afferents within spinal ganglia that is characteristic after nerve injury is noticeably absent from trigeminal ganglia [30, 31].

\section{TRIGEMINAL NEUROPATHIC PAIN}

\subsection{Microglia Respond to Trigeminal Nerve Injury}

One of the most common causes of chronic orofacial pain is as a consequence of direct nerve injury after surgery, for example third molar extraction [32]. To address the mechanisms behind this phenomenon, various models of trigeminal nerve injury have been developed. In the trigeminal system, ligation or transection of the ION and inferior alveolar nerve (IAN) are the most commonly used models to study trigeminal injury [33-35]. Early attempts to analyze microglial activation and proliferation were performed after ION injury and whisker follicle removal $[36,37]$ and more recently IAN injury [33]. In each case, the location of the microglial response corresponded to the central terminals of trigeminal primary afferents as detailed in the anatomical tracings of the ION and IAN [38, 39]. In the case of whisker follicle removal, the microglia response matched the known somatotopy in the Sp5C and other subnuclei [37]. Microglia reactions to ION injury were concentrated particularly in the superficial layers of the $\mathrm{Sp5C}$, suggesting an exaggerated response to the central terminals of C-fiber afferents, specifically $[23,37]$. On the other hand, microglial reaction to sciatic nerve injury was greater in the deeper lamina where myelinated fibers terminate [36]. Interestingly, no microglia reactions were found at the second and third synapses of the trigeminal sensory relay after nerve injury [36]. Though yet to be confirmed in other nerve injury models, this finding emphasizes the important contribution of direct primary afferent contact to microglial activation after peripheral nerve injury [37]. Interestingly, microglia hyperactivity has been 
detected in the rostral ventromedial medulla after chronic constriction injury (CCI) of the ION in adult rats, suggesting involvement in the descending modulation of pain transmission, although a similar response was observed in sham operated animals [40].

\subsection{Functional Microglia Response}

It has previously been shown that activation of microglia occurs in the superficial layers of the Sp5C after transection of the IAN and mental nerve [33]. The microglial response was maximal $3-7$ days after injury, indicated by elevated expression of the microglial marker cluster of differentiation molecule 11b (CD11b; also known as complement receptor3; OX-42) and phosphorylated p38-mitogen activated protein kinase (MAPK). The microglia response also corresponded to the same region of c-Fos expression detected in the $\mathrm{Sp} 5 \mathrm{C}$ after nerve injury [33]. The development of mechanical allodynia in a similar rat model involving chronic constriction of the IAN was attenuated by administration of the p38-MAPK inhibitor SB203580 [41]. Recently, partial ION injury has been shown to induce glial changes in the region of the caudal medulla in the mouse [35]. An up-regulation of CD11b was observed as early as one day after injury. Further, a proportion of these cells was found to contain bromodeoxyuridine (BrdU) suggesting the proliferation as well as 'activation' of microglia in this region.

\subsection{Trigeminal-Specific Neuropathies}

\subsubsection{Migraine}

Despite many years of theory relating migraine to dilation of the cranial vasculature, accumulating evidence points to central sensitization in the persistence and perhaps generation of migraine pain $[9,42]$. Chemical stimulation of the rat dura can produce sensitization of $\mathrm{Sp5C}$ neurons to subsequent periorbital mechanical stimulation; once initiated, this central sensitization results in a long-lasting mechanical hypersensitivity that can no longer be attenuated by peripheral nerve block [43]. In a similar experiment, the activity of spinal trigeminal nucleus neurons to mechanical and thermal stimulation of the periorbital skin could be normalized by intravenous administration of cyclooxygenase 1 (COX1) and COX2 inhibitors [44]. Cyclooxygenase is known to be upregulated in ischaemic [45] and epileptic [46] brain pathologies, as well as after spinal cord injury [47] with increased expression of both isoforms seen in microglia.

Recently, there has been success in the use of the pan opioid receptor blocker naloxone as a prophylactic treatment for migraine patients; an almost counterintuitive result that may be linked to effects on microglia [48]. It has been reported that morphine can induce COX1 expression in microglia, and inhibition of microglia with minocycline significantly potentiated the analgesic effect of systemic morphine [49]. Together with other reported effects of opioids on microglia [50], including $\mathrm{P} 2 \mathrm{X} 4$ receptor up-regulation [51], these results suggest that microglial activation may play a role in migraine pathology.

\subsubsection{Trigeminal Neuralgia}

Recently, multiple sclerosis-related trigeminal neuralgia was found to correlate with lesions of central projections of primary afferents in the spinal trigeminal nucleus [52, 53]. Microglia represent a likely candidate for mounting an im- mune response to demyelination of trigeminal afferents. In multiple sclerosis, or the animal model autoimmune encephalomyelitis, microglia respond to a lesion by phagocytosing damaged tissue and promoting neural regeneration [54]. Ironically, it is perhaps these mechanisms that are detrimental in the case of nociceptive primary afferent neurons [55]. In the case of multiple sclerosis-related trigeminal neuralgia, a relapse-remitting form of the disease may lead to a synchronous microglia reaction to the central projections of primary afferents that could be responsible for spontaneous, trigeminal neuralgia-like pains.

\section{TRIGEMINAL INFLAMMATORY PAIN}

\subsection{Microglia Respond to Inflammatory Insult}

Formalin injection into the facial area of adult rats induces up-regulation of several microglial markers in the superficial region of the $\mathrm{Sp} 5 \mathrm{C}$, including the major histocompatability complex (MHC) class I and class II antigens OX18 and OX-6, respectively, as well as OX-42 [56]. Inflammatory irritants, such as mustard oil, also have the ability to increase facial receptive field size [57]. Prevention of this inflammation-induced central sensitization by inhibition of p38-MAPK has been suggested to involve a microglial mechanism [58]. In the spinal cord there exists two p38MAPK isoforms - alpha and beta - which are expressed in neurons and microglia, respectively [59]. All known p38MAPK isoforms are thought to play a role in inflammatory responses [60], therefore pharmacological experiments must consider the specific role of each isoform with respect to neuron and microglia functions.

Subcutaneous injection of an inflammatory agent to the facial area produces a microglia response in the Sp5C [56], whereas injection to a deep orofacial region has been shown to elicit a strong astrocyte reaction in the Sp5I/Sp5C boundary [61]. These results are in keeping with tracing studies showing that cutaneous inputs are received by the Sp5C, whereas fibers innervating deep tissues of the orofacial area terminate preferentially at the Sp5I/Sp5C boundary [15]. The Sp5C and Sp5I/Sp5C boundary have both been strongly implicated in the processing of incoming nociceptive information [62]. As mentioned earlier, trigeminal nociceptive afferents projecting to the $\mathrm{Sp} 5 \mathrm{C}$ and $\mathrm{Sp} 5 \mathrm{I} / \mathrm{Sp} 5 \mathrm{C}$ regions may vary in the degree of peptidergic versus non-peptidergic $\mathrm{C}$-fibers. Do the inflammatory reactions in the different regions represent different activating processes, or merely reflect anatomical differences? Unlike the spinal cord, the trigeminal system appears unique in its degree of intra- and intersubnuclear signaling [63]. Further studies of this signaling network may allow a functional dissection of injury-specific neuropathies that is not possible in spinal pain models and may reveal mechanisms of central sensitization specific to the trigeminal system $[1,64]$.

\subsection{Astrocyte Response}

Inflammation-induced trigeminal hypersensitivity could be attenuated by the aconitase inhibitor fluorocitrate, suggesting astrocyte metabolism is also a necessary factor in the development of trigeminal central sensitization [57]. In response to an injection of the inflammatory agent complete Freund's adjuvant into the rat massetter muscle, an astrocyte reaction - in the form of an elevated glial fibrillary acidic 
protein (GFAP) signal - was observed at the Sp5I/Sp5C boundary [61]. The authors present evidence that interleukin (IL) $-1 \beta$ is released from astrocytes and can phosphorylate the NR1 subunit of the N-methyl-D-asparate (NMDA) receptor via a phospholipase C (PLC)/protein kinase C (PKC) pathway [61]. Further evidence suggests that substance $P$ release from trigeminal afferents, leading to elevated nitric oxide, may be the initial trigger for astrocyte reactivity [61]. This proposed mechanism of central sensitization of trigeminal neurons fits with the description of GFAP-positive astroctyes seen at the electron microscopic level in close apposition with substance P-positive primary afferent terminals in the Sp5C [65].

The historic view of astrocyte function as support cells of the CNS has, not surprisingly, been reassessed in light of new evidence for a more engaging role in neuronal function. Glutamate has in fact been found to play an integral role in direct signaling between astrocytes and neurons [66]. Instead of merely sequestering glutamate spill-over from synaptic activity, astrocytes convert the acquired glutamate to glutamine, which in turn is 'shuttled' back to the neurons. Inhibition of a key enzyme involved in this process, glutamine synthetase (GS), has been shown to reverse the sensitization of Sp5C neurons that occurs within the first hour of an irritant (mustard oil) applied to the rat tooth pulp [67]. This suggests that astrocytes, at least in terms of their glutamate recycling capacity, can have a direct effect on the behavior of central trigeminal neurons in response to an inflammatory insult directed to peripheral trigeminal nerves. For a further description of the role of astrocytes in neuron-glia interactions in the trigeminal sensory system readers are directed to two excellent recent reviews [58, 64].

\section{NEURON TO MICROGLIA SIGNALLING}

The pattern of microglia activation after injury appears linked to the central projections of trigeminal primary afferents, in particular those of unmyelinated C-fibers. However, the nature of the triggering factor(s) that lead to microglia activation remain enigmatic. Peripheral nerves are abnormally activated by nerve injury and inflammation. These hyper-activated primary afferent nerve terminals release various neurotransmitters and substances that may have long term effects on secondary neurons and glia in the CNS.

\subsection{Primary Afferent Activity Triggers Trigeminal Cen- tral Sensitization}

Microglia isolated from the hippocampus of epilepsy patients show relatively activated properties [68], suggesting microglia respond to excessive neuronal activity in the brain. The activity of Sp5C neurons is increased after trigeminal nerve injury [34], reflecting an enhanced excitability or 'sensitization' of second-order trigeminal neurons [69]. The integrity of the $\mathrm{Sp5C}$ is critical for the processing of nocicpeptive signaling in the trigeminal spinal nucleus [70]. Morphine injected into the $\mathrm{Sp5C}$ inhibits the nociceptive responses of Sp5O neurons [71] and central sensitization in the $\mathrm{Sp5O}$ has been shown to be dependent on adenosine 5'triphosphate (ATP)-gated $\mathrm{P} 2 \mathrm{X}$ receptors within the $\mathrm{Sp} 5 \mathrm{C}$ [72]. Finally, central sensitization of thalamic relay neurons by mustard oil application to the tooth pulp was prevented by block of synaptic transmission of $\mathrm{Sp5C}$ neurons by cobalt application [73].
A number of studies have shown the activity of Sp5C neurons to be directly modulated by $\mathrm{C}$-fiber stimulation. The propagation of excitation within the $\mathrm{Sp} 5 \mathrm{C}$ by tetanic afferent stimulation in vitro was shown to be dependent on C-fiber innervation; the response was absent in rats that were previously exposed to neonatal capsaicin treatment, which caused the selective loss of unmyelinated $\mathrm{C}$-fiber afferents to the Sp5C [74]. In vivo, noxious C-fiber stimulation of cutaneous facial afferents led to an increase in the activity of Sp5C neurons as measured by extracellular recording [5], as did mustard oil application to the tooth pulp [75]. The induction of long term potentiation (LTP) in the spinal cord by stimulation of C-fibers of the sciatic nerve - either electrically or by capsaicin application - was recently shown to result in a mechanical hypersensitivity; behavioral changes were mirrored by an increase in ionized calcium-binding adaptor molecule1 (Iba-1) immunoreactivity in spinal microglia and change in microglial morphology [76]. Furthermore, the behavioral sensitization and microglial activation could be prevented by the microglial metabolic inhibitor minocycline [76]. Interestingly, levels of activating transcription factor-3 (ATF-3) remained low, and the pattern of CGRP-positive and IB4positive terminals remained unchanged, suggesting a lack of axonal damage during stimulation. The response therefore appeared to be driven purely by the activity of unmyelinated primary afferents. Consistent with this result, complete nerve block with bupivucaine prior to spared nerve injury of the rat sciatic nerve prevented the activation of p38-MAPK in spinal microglia [77]; however, bupivucaine applied after injury could not reverse the microglial changes. These results suggest that primary afferent activity, leading to microglial activation, are the initiating factors in spinal and possibly trigeminal central sensitization.

\subsection{Central Degeneration and/or Regeneration}

Morphological or chemical changes may occur to primary afferents as they attempt to recover from physical or chemical injury. It has been reported that factors released from damaged sensory neurons in vitro can induce glial cell activation when applied to the spinal cord [79]. Death of neurons in the trigeminal mesencephalic nucleus by ricin injection of the trigeminal nerve induced microglial activation characterized by an increase in tyrosine phosphorylation, followed by the appearance of an amoeboid microglial morphology [80]. The authors further suggest that elevation of tyrosine kinase activity is an early event in the microglial response to nerve injury [81]. After corneal infection with herpes simplex virus (HSV), microglia in the trigeminal spinal nucleus appear to respond to apoptosis of terminal dUTP nick end labeling (TUNEL)-positive neurons [82]. At rest, brain stem microglia displayed faint immunoreactivity for Iba-1 which became significantly up-regulated in the vicinity of virally infected afferents.

Gasserian (trigeminal ganglion) rhizotomy in the cat led to postsynaptic thickening of second-order trigeminal neurons in the Sp5I suggestive of deafferentiation [83]. Evidence exists supporting a role for microglia (and astrocytes) in phagocytosing degenerative primary afferents in the trigeminal nuclei after nerve transection; the glial cells were found to contain axon debris as early as seven days postoperative [84]. On the other hand, no evidence of phagocytosis was observed in the superficial layer of the Sp5C sur- 
rounding the microglia response to formalin injection in the rat [56]. The function of the microglia response may therefore depend on the type and severity of peripheral injury, for instance inflammatory versus neuropathic transection injury.

A method of quantifying microglial activation after spinal nerve injury has been developed by Beggs and Salter [85]; their results demonstrated that the activation of microglia had spread outside the field of central terminals of the injured nerve. Such an enlargement of the area of microglial response may provide the substrate for the reshaping of facial receptive fields in the trigeminal spinal nucleus $[57,86]$. In spinal cord, sprouting of A-fiber afferents to substantia gelatinosa neurons has been demonstrated after spinal nerve injury [87] and appears dependent on C-fiber activation [88]. Regeneration of primary afferents leading to an increase in receptive field size has been proposed as a mechanism of central sensitization after IAN transection in rat [34]; the same model having previously been used to demonstrate microglial up-regulation in the Sp5C [33].

Neosynaptogenesis of primary afferents caused by a lesion of the contralateral facial sensory motor cortex has recently been documented in the Sp5C of the rat [89]. Intriguingly, the authors point to C-fibers targeting the superficial $\mathrm{Sp} 5 \mathrm{C}$ as one of the predominant fiber-types observed in the plastic response. The question of whether microglia play a role in this regeneration effect remains unanswered but we may find clues to their function by contrasting with the microglial response to peripheral nerve injury. After ION injury, microglia reactions in the spinal nucleus have been observed up to 60 days post injury [37]; this indicates that in certain cases microglia may perform an additional long-term role that parallels the time course of either degeneration or reorganization of trigeminal primary afferents.

\subsection{Chemical Release Factors}

Numerous substances released from peripheral neurons, such as glutamate [90] and ATP [91] have been shown to affect the microglial state. Platelet-derived growth factor (PDGF) and substance P from dorsal root ganglion neurons can activate microglia in the spinal cord through PDGF betareceptors [92] and neurokinin-1 (NK-1) receptors [93], respectively, that are expressed on microglia.

The fractalkine receptor, CX3CR1, is a useful immunohistochemical and functional marker for brain microglia [94]. Ligand binding of CX3CR1 initiates MAPK and phosphatidlyinositol-3 kinase signaling cascades leading to migration and morphological changes via actin rearrangement in microglia [95]. Fractalkine-CX3CR1 signaling is also a putative mechanism of direct contact between neurons and microglia [96]. Fractalkine (the CX3CR1 ligand) is expressed in neurons, where it either remains bound to the cell membrane or is cleaved and released as a soluble form of neuronal fractalkine (sFNK) [96, 97].

Intrathecal injection of sFNK has been shown to induce mechanical allodynia and thermal hyperalgesia in the rat [97]. Further, endogenous sFNK from peripheral neurons amplified microglia activation, and maintained central sensitization via its interaction with CX3CR1 on microglia [97]. It has recently been demonstrated that noxious-like electrical stimulation of the dorsal root of spinal cord slices from neu- ropathic rats led to increased sFNK release from primary afferent neurons [98]. In addition, it was shown that membrane-bound fractalkine cleavage, resulting in release of the soluble form sFNK, was mediated by the proteolytic enzyme cathepsin S, which was released from microglia [98]. This final result intriguingly suggests that initial microglia activation, by an as yet unknown signal, is up-stream of sFNK release.

In contrast to sFNK, recent evidence suggests that membrane bound fractalkine-CX3CR1 binding by direct contact between neurons and microglia may instead act to attenuate microglial activation [99]. Microglia also express another receptor, CD200R, that has a counterpart ligand, CD200 (OX2), at the neuronal membrane [100]. Again, interaction between neuronal CD200 and the microglial receptor CD200R is purported to decrease microglial activation [100]. These data suggest that neuron-microglia contact is necessary for maintaining microglia in a quiescent state [101]. It is wholly possible that this neuron-microglia contact may be lost in the case of deafferentiation, inferring consequences for microglial activation in trigeminal and spinal superficial dorsal horns after peripheral nerve injury.

\section{GLIA-NEURON SIGNALLING IN TRIGEMINAL GANGLIA}

Trigeminal neuropathies associated with peripheral mechanisms represent a major contribution to orofacial pain after nerve injury [102]. Glia-neuron signaling may therefore not only be important in the spinal nucleus of the trigeminal nerve but also within the trigeminal ganglia that contain the cell bodies of trigeminal afferent neurons.

\subsection{Neuropeptides in Trigeminal Ganglia}

The relevance of CGRP to painful trigeminal conditions has received particular attention with respect to migraine pathophysiology [103]. Circulating levels of CGRP are known to be elevated during migraine attack [104] and CGRP receptor antagonists show promise as effective therapies in migraine treatment [105]. Previous hypotheses on migraine pathophysiology have included mechanisms of neurogenic inflammation, such as the vasodilator function of CGRP released from the peripheral terminals of trigeminal afferents in the dura mater [9].

Mediators released from trigeminal satellite glia after IL$1 \beta$ or nitric oxide (NO) treatment, were able to facilitate capsaicin-induced release of CGRP [106]. Though the mechanism behind this response was not explored further, it points to an activity-dependent hyperexcitability of trigeminal C-fibers after inflammation. It has been shown previously that CGRP can itself promote NO release from satellite glia [107], feasibly continuing the cycle of release through a paracrine feedback mechanism. Indeed, the close apposition of satellite glia cells and neurons in the trigeminal ganglia after inflammation [108] appears to support their chemical interaction. These data suggest an additional function of CGRP at the trigeminal ganglia in promoting neuronal excitability.

\subsection{Purinergic Receptors in Trigeminal Ganglia}

Purinergic receptors on trigeminal ganglia neurons and satellite glia have been characterized using an in vitro cul- 
ture [109]. The study demonstrated that the response of trigeminal neurons to an agonist acting at the ATP-gated ion channel P2X3 increased soon after application of the proinflammatory agent bradykinin. After 24 hours exposure to bradykinin the responsiveness of neurons to P2X3-receptor activation returned to control; however, the percentage of responsive neurons had decreased. The response of satellite glia to metabotropic $\mathrm{P} 2 \mathrm{Y}$ receptor activation, on the other hand, increased after chronic exposure of bradykinin [109]. These results suggest that neuronal P2X3 receptors may be involved in the early stages of trigeminal neuroinflammation, while satellite glia $\mathrm{P} 2 \mathrm{Y}$ receptors may mediate a long-term response.

In dorsal root ganglia, $\mathrm{P} 2 \mathrm{X} 3$ has been shown to be almost exclusively expressed in non-peptidergic, IB4-positive neurons $[110,111]$. In trigeminal ganglia, however, a moderate percentage of IB4-negative, peptidergic (CGRP-positive) neurons also express the $\mathrm{P} 2 \mathrm{X} 3$ receptor [112]. The coexpression of CGRP with the P2X3 in IB4-negative trigeminal ganglia is also increased after tissue inflammation [113]. Long-term exposure of cultured trigeminal ganglion neurons to CGRP has been shown to increase the amplitude of P2X3mediated ionic currents and speed the recovery of the receptor from desensitization [114]. Intriguingly, the authors note the time course of P2X3 up-regulation by CGRP to be consistent with the known onset of migraine pain. Increased $\mathrm{P} 2 \mathrm{X} 3$ protein has also been detected in trigeminal ganglia after IAN injury [115] and partial ligation of the ION [116]. In addition, P2X3-containing receptors have been identified in lamina II of the Sp5C [112], where the activation of the $\mathrm{P} 2 \mathrm{X} 2 / 3$ receptor subtype located pre-synaptically has been shown to facilitate the release of glutamate from trigeminal afferents [117].

ATP release is thought to be intrinsic to astrocyte communication and the propagation of $\mathrm{Ca}^{2+}$ waves therein, and current evidence suggests that similar communication may also occur between astrocytes and neurons [118]. The close physical relationship observed between astrocytes and nerve terminals in the Sp5C [65] provides the infrastructure for activation of pre-synaptic $\mathrm{P} 2 \mathrm{X}$ receptors. If it were the case that CGRP release in response to astrocyte IL- $1 \beta$ release [106] also occurs at the central terminals of trigeminal nociceptive afferents [61], an interesting mechanism can be proposed: The presence of reactive astrocytes in the superficial Sp5C region may affect primary afferent nociceptive neurons via sequential CGRP and P2X3 mechanisms, which, in coordination with ATP release from astrocytes, may lead to self-enhanced glutamatergic neurotransmission in the Sp5C. Interestingly, central sensitization in the $\mathrm{Sp} 5 \mathrm{C}$ and $\mathrm{Sp} 5 \mathrm{O}$ after mustard oil (MO) application to the tooth pulp was attenuated by intrathecal administration of $\mathrm{P} 2 \mathrm{X}$ receptor antagonist in the Sp5C [72]. Further experiments revealed that endogenous activation of $\mathrm{P} 2 \mathrm{X}$ receptors was involved in the Sp5C central sensitization, and that sensitization spread to the $\mathrm{Sp} 5 \mathrm{O}$ in a P2X receptor-dependent manner [72, 75]. Could pre-synaptic $\mathrm{P} 2 \mathrm{X}$ receptor activation, via the "purinergic regulatory complex", as proposed by Kato et al. [119] be relevant to the mechanisms of migraine pathophysiology?

\subsection{Cytokines in Trigeminal Ganglia}

After HSV infection of the trigeminal nerve, Iba-1 positive microglia-like cells in the trigeminal ganglia co-express basic fibroblast growth factor suggesting a neuroprotective function [82]; this is in contrast to microglia in the trigeminal spinal nucleus, which - in the same study - appear to adopt a phagocytic phenotype in response to neuronal apoptosis. Interestingly, the authors observe an increased expression of the cytokine tumor necrosis factor (TNF)- $\alpha$, which colocalizes not with Iba-1 but with GFAP, indicating astrocytelike satellite cells as the source of the cytokine [82].

The cytokine IL- 6 can induce microglial activation and ATF-3 over-expression in spinal dorsal horn [120]. The study by Latremoliere et al. found over-expression of IL-6 in the spinal dorsal horn of sciatic nerve CCI rats but not in the Sp5C of ION-CCI rats, suggesting IL-6 signaling may be a critical factor in somatic neuropathic pain but not trigeminal neuropathic pain after CCI nerve injury [120]. The potent pro-inflammatory cytokine IL-1 $\beta$ has also been implicated with GFAP-positive glial cells in trigeminal ganglia following injection of complete Freund's adjuvant to the whicker pad of the rat [108]. In primary cultures of trigeminal satellite glial cells, IL-1 $\beta$ has been demonstrated to elevate release of prostaglandin $\mathrm{E}_{2}\left(\mathrm{PGE}_{2}\right)$ from GFAP- and GSpositive cells, via the inducible form of COX, COX2 [106]. Other proinflammatory cytokines, such as interferon (IFN)$\gamma$, and TNF- $\alpha$, had no effect on PGE 2 levels [106].

\section{MICROGLIA VERSUS ASTROCYTE MECHA- NISMS}

The results described above represent an interesting possible distinction between glial cell functions. Astrocyte mechanisms, involving IL-1 $\beta$ release, may affect neuronal excitability by increasing nociceptor activity directly [121] or through NMDA receptor phosphorylation [61]. On the other hand, microglial mechanisms, elucidated in the spinal cord, appear more complex and have suggested an IFN- $\gamma$ pathway to central sensitization [122]: IFN- $\gamma$ signaling is believed to be the prerequisite to P2X4 receptor up-regulation [122], leading to brain-derived neurotrophic factor (BDNF) release [123] and the downregulation of the potassium/chloride cotransporter, KCC2. In turn, decreased $\mathrm{KCC} 2$ activity may reverse the response of spinal projection neurons to gammaaminobutyric acid (GABA) from inhibitory to excitatory [78] The molecular mechanisms relating to microglia activation are discussed further in later sections.

The time course of microglial and astrocyte reactions is known to differ, with the microglial response generally considered to be the earliest after injury [33]; indeed there is evidence to suggest that the astrocyte GFAP response is secondary to microglial activation [124]. Whether the two cytokine pathways summarized above operate concertedly or independently to induce neuronal hyper-excitability is currently unknown, though in the spinal cord, at least, cytokine pathways may have multiple and overlapping functions [125].

By coincidence or otherwise, the majority of microglial studies in neuropathic pain have focused on the spinal system $[123,126]$, whereas recent data on astrocyte mechanisms have been obtained in the trigeminal system [57, 61, 
67], though not exclusively [127]. The preference of inflammatory pain models in the trigeminal system compared to neuropathic pain models in the spinal system, perhaps due to technical limitations and the shift to mouse models in spinal studies, may explain the divergent mechanisms appearing in the literature. Undoubtedly, microglial and astrocyte mechanisms are at play, which appears the case at least after nerve injury in the trigeminal system $[33,35]$.

\section{MICROGLIA}

Microglia can be described as resident macrophages of the CNS. They are widely distributed in all regions of the brain and spinal cord and display a ramified morphology described as 'resting' in physiological conditions. Resting microglia possess highly dynamic processes, which perform a surveillance role in the CNS [128-130]. In certain pathophysiological conditions, microglia transform into an 'activated' state: a phenotype described by morphological changes, expression of various inflammatory mediators, as well as migration and proliferation activity [131-133].

The majority of studies to date have been performed on microglia isolated from brain; however, the literature available on microglial properties after nerve injury, particularly in the trigeminal and spinal systems, remains limited [134, 135]. In the second part of our review we wish to discuss the intrinsic membrane properties of microglia, and the markers, receptors and ion channels therein, that may bear reference to the role of microglia in the trigeminal sensory system.

\subsection{Microglial Markers}

Microglia may be identified by various expression markers that also offer clues to their activation status [101]. Two of the most commonly used markers are CD11b (OX-42), an antigen representing cells of a myeloid lineage, and Iba-1, a calcium binding protein shown to be involved in membrane ruffling [136]. Iba-1 is also up-regulated by pathological conditions such as cerebral ischaemia [137], and in macrophage at least may be up-regulated by IFN- $\gamma$ [138]. Lipocortin-1 (LC1), a member of the annexin protein family, has also been used as a brain-specific microglial marker [37].

\subsection{Metabotropic Receptors}

Metabotropic or G-protein-coupled receptors play a role in microglial activation via two mechanisms: activation of signaling molecules and elevation of intracellular calcium levels. Intracellular signal cascades are mediated by several highly expressed microglial membrane proteins. Elevation of intracellular calcium levels in microglia by metabotropic receptors has been widely reported, such as by metabotropic glutamate receptors [139], muscarinic receptors [140], histamine receptors [141], purinergic P2Y receptors [142], CC chemokine receptors [143] and toll-like receptors [141]. Moreover, many metabotropic receptors may share dual roles by triggering intracellular signaling cascades and/or $\mathrm{Ca}^{2+}$ rises that can alter membrane protein expression as well as the production of many cytokines and chemokines. The release of such effector molecules seems critical to changes in neuronal plasticity and central sensitization [144].

\subsubsection{Inflammatory Mediator Receptors}

Each phenotype associated with microglia activation could be a direct consequence of specific signaling path- ways. For example, activation of IFN- $\gamma$ receptor activates microglia via Lyn kinase activation [122], and beta chemokine receptor activation is linked to extracellular signal-related kinase 1 (ERK1), ERK2 and MAPK pathways [145]. Toll-like receptor activation by lipopolysaccharide (LPS) has been shown to stimulate the p38-MAPK pathway and production of matrix metalloproteinases, which may relate to cleavage of pro-IL-1 $\beta$ [146, 147]. Further elucidation of these and other receptor-mediated pathways in microglia of the neuropathic trigeminal system may indicate their relevance to phenotypes such as morphological change, migration, proliferation, and further cytokine and/or chemokine release.

\subsubsection{Metabotropic Glutamate Receptors}

Microglia express a surprising number of neurotransmitter receptors [148]. Glutamate is the most fundamental neurotransmitter for excitatory synaptic signaling in the brain. Metabotropic glutamate receptors (mGluRs) consist of three groups of receptors (group I, II, III) and all have been identified on microglia. mGluR5, a group I mGluR, has been found in spinal as well as brain microglia [139]. Activation of mGluR5 by the specific agonist (RS)-2-chloro-5hydroxyphenlglycine (CHPG) inhibited microglial activation in response to spinal cord injury [149] and the inflammatory mediator, LPS [150]. CHPG reduced the levels of galectin-3, TNF-a, NADPH oxidase components and inducible nitric oxide synthase via a $\mathrm{Ga}$ protein/PLC/PKC pathway, as well as reducing the levels of ED1 (a lysosomal marker found in activated phagocytes) and Iba-1 [150]. CHPG also attenuated microglial-induced neuronal toxicity and led to a decreased inflammatory response [149-151].

Functional expression of group II mGluRs, mGluR2 and mGluR3, have been reported in microglia, which appear to evoke an 'activation' response. Activation of each receptor led to a neurotoxic microglia activation which was blocked by a corresponding mGluR-specific antagonist [152]. Furthermore, the group II mGluR agonist chromogranin A (CGA) induced microglial activation and neurotoxicity in a manner similar to amyloid plaques in Alzheimer's disease and was attenuated by mGluR blockade [152]. Among group III mGluRs, mGluR4, mGluR6 and mGluR8 have been identified on microglia. Group III mGluR activation induced a mild level of microglial activation, as confirmed by enhanced signal of ED1 but did not cause neurotoxicity. Interestingly, microglial reactivity and neurotoxicity induced by LPS, CGA and amyloid $\beta(A \beta)$ was reduced by a group III mGluR-specific agonist [153].

The above evidence suggests that metabotropic glutamate receptor activation may be correlated with changes in the activation state of microglia. The presence of glutamate receptors provides microglia with the potential to directly respond to nerve activity, such as excessive glutamate release from primary afferents in the Sp5C likely after trigeminal nerve injury. Measurement of the response to metabotropic receptor activation or the up- or down-regulation of molecular markers, either by immunohistochemistry or molecular techniques, can reveal clues to the activation status of microglia. However, these techniques offer low temporal resolution of the time course of microglial activation. 


\subsection{P2X Receptors in Microglia}

Great advance in microglial physiology has been made using electrophysiology to understand changes to microglial membrane properties down to the millisecond timescale [154-157]. Despite being a 'non-excitable' cell, microglia express a wide variety of ion channels that govern cell functions in resting and activated states [158].

$\mathrm{K}^{+}$channels, $\mathrm{Na}^{+}$channels, voltage-activated $\mathrm{Ca}^{2+}$ channels, $\mathrm{Ca}^{2+}$-release activated $\mathrm{Ca}^{2+}$ channels, $\mathrm{Cl}^{-}$channels, $\mathrm{H}^{+}$ channels, as well as ionotropic P2X, glutamate and GABA receptors have all been identified in varying states of microglial activation [90, 158-160]. The expression profile of microglial ion channels is dynamic and the ion channels themselves may play a critical role in microglial activation and response [123, 161]. The study of microglial membrane conductances to measure ion channel function is therefore an accessible paradigm to examine the early mechanisms of microglial activation.

$\mathrm{P} 2 \mathrm{X}$ receptors are thought to be expressed in several different activation states of microglia. As ionotropic receptors gated by ATP, their role in microglia is likely to allow $\mathrm{Ca}^{2+}$ influx and initiate $\mathrm{Ca}^{2+}$-dependent intracellular responses [162]. P2X4 and P2X7 receptor subtypes in particular appear to play crucial roles in neuropathic and inflammatory pain [163, 164]; however, little is known about their functional role in microglia. Although $\mathrm{P} 2 \mathrm{X} 4$ receptors are rarely expressed in 'resting' adult microglia (except near blood vessels [165]), microglia in animal models of neuropathic pain show up-regulation of $\mathrm{P} 2 \mathrm{X} 4$ receptors in a Lyn tyrosine kinase-dependent manner [166]. The presence of P2X4 is also necessary for the release of BDNF from microglia [123]. P2X7 receptors are also expressed in microglia where their function is, in part, related to IL-1 $\beta$ release [167]. Microglial P2X4 receptors have become synonymous with microglial activation $[51,55,123,126,168,169]$. ATP can itself up-regulate $\mathrm{P} 2 \mathrm{X} 4$, as well as p38-MAPK, in spinal microglia [170]. ATP applied to the spinal cord was shown to induce LTP of C-fiber-evoked field potentials, suggesting a purinergic mechanism may be relevant to central sensitization of spinal neurons [170]. However, the critical function of the $\mathrm{P} 2 \mathrm{X} 4$ receptor, either via $\mathrm{Ca}^{2+}$ signaling or protein interactions, and more importantly the mechanisms of its activation, remain to be elucidated.

Microglial properties often compare with that of macrophage following macrophage differentiation [158]. A study of $\mathrm{P} 2 \mathrm{X}$ receptors in peritoneal macrophage revealed functional $\mathrm{P} 2 \mathrm{X} 1$, as well as $\mathrm{P} 2 \mathrm{X} 4$, receptor responses in minimally activated macrophages [171]. In order to record the fast-desensitizing $\mathrm{P} 2 \mathrm{X} 1$ response the authors briefly cultured the macrophage in the presence of an enzyme to degrade endogenous ATP in the extracellular milieu; this suggests that $\mathrm{P} 2 \mathrm{X} 1$ receptor activation is likely to be the first microglial response to an ATP signal [171]. Immunohistochemical experiments have demonstrated $\mathrm{P} 2 \mathrm{X} 1$ receptor expression in microglia in early development [165]; understanding their functional role in microglia may add an interesting facet to microglial purinergic signaling.

\subsection{Potassium Channels in Microglia}

$\mathrm{K}^{+}$channels have been suggested as one of the most important ion channels in governing microglial intrinsic mem- brane properties and homeostasis. Comparing electrophysiological studies of microglia recorded in isolated culture, acute and cultured brain slices reveals functional differences in the expression of $\mathrm{K}^{+}$channels. Delayed rectifier $\mathrm{K}^{+}$currents were more prominent in microglia in brain slice cultures than in microglia from acute slices [172]. Cultured microglia exposed to astrocyte-conditioned medium (ACM) display up-regulated delayed rectifier $\mathrm{K}^{+}$channel function via a mechanism of serine/threonine kinase activation [173]; in addition, ACM-treated microglia transform from amoeboid into ramified morphology. These observations suggest that microglia adopt a different state depending on the experimental conditions and that $\mathrm{K}^{+}$currents are a functional marker for these changes.

Evidence suggests that $\mathrm{K}^{+}$channels may be directly involved in microglial activation, as well as the release of inflammatory mediators. The enhanced expression and production of the pro-inflammatory cytokines IL-1 $\beta$, IL-6, IL-8 and TNF- $\alpha$ by chronic treatment of $A \beta$ peptide in microglia, via a p38-MAPK pathway, could be inhibited by the broadspectrum $\mathrm{K}^{+}$channel blocker, 4-aminopyridine (4-AP) [161]. This result also suggests that $\mathrm{K}^{+}$channel activity may be linked to p38-MAPK activation. $\mathrm{K}^{+}$efflux through 4-AP sensitive channels has also been suggested to optimize the function of the enzyme capase- 1 , a critical step in the release of mature IL-1 $\beta$ [174].

The expression of three different types of $\mathrm{K}^{+}$channels has been confirmed in microglia: inward rectifier channels, voltage-gated 'delayed rectifier' channels, and $\mathrm{Ca}^{2+}$-activated $\mathrm{K}^{+}$channels. As we discuss, these channels appear to regulate microglial proliferation, migration, and the release of cytokines and chemokines.

\subsubsection{Inward Rectifier Potassium Channels}

Inward rectifier $\mathrm{K}^{+}$channels $\left(\mathrm{K}_{\mathrm{ir}}\right)$ are open at negative membrane potentials and close in response to membrane depolarization; their voltage-dependence allows $\mathrm{K}^{+}$efflux positive to the $\mathrm{K}^{+}$reversal potential (around $-80 \mathrm{mV}$ in microglia [175]). Several reports indicate that microglial cells with more negative resting membrane potentials have stronger $\mathrm{K}_{\mathrm{ir}}$ channel activity, and vice versa, suggesting these channels directly regulate the microglial resting membrane potential [175-177]. $\mathrm{K}^{+}$currents recorded in microglia were strongly activated by membrane hyperpolarization and were inhibited by external $\mathrm{Ba}^{2+}, \mathrm{Cs}^{+}$and quinine applications $[155$, 178]. The molecular identity of these microglia channels was suggested to be $\mathrm{K}_{\mathrm{ir}} 2.1$ channels using reverse transcriptase polymerase chain reaction (RT-PCR) experiments in the microglia cell line, BV-2 [179]. In culture, microglia exhibit prominent $\mathrm{K}_{\mathrm{ir}}$ channel current, with an apparent lack of other $\mathrm{K}^{+}$channel activity $[176,180]$. Unstimulated microglial cells are dominated by a $\mathrm{K}_{\mathrm{ir}}$ conductance in culture [181]. Microglia activated by LPS show a down-regulation of $\mathrm{K}_{\mathrm{ir}}$ channels; this change is accompanied by up-regulation of another $\mathrm{K}^{+}$current $[178,182]$. These data indicate that $\mathrm{K}_{\mathrm{ir}}$ channels are expressed in relatively 'resting' (non-stimulated) microglia and are down-regulated in the 'activated' state. However, studies also suggest that $\mathrm{K}_{\mathrm{ir}}$ channels are involved in process of microglial activation. Blockade of $\mathrm{K}_{\mathrm{ir}}$ by $\mathrm{Ba}^{2+}$ inhibited microglial proliferation in colony-stimulating factor-1-treated microglia [180] and facial nerve axotomy led to 
an up-regulation of $\mathrm{K}_{\text {ir }}$ channels in microglia within $12 \mathrm{~h}$ [134]. The relationship between $K_{\text {ir }}$ channel function and the time course of microglial activation remains to be elucidated.

\subsubsection{Voltage-Gated 'Delayed Rectifier' Potassium Chan- nels}

Delayed rectifier $\mathrm{K}^{+}$channels $\left(\mathrm{K}_{\mathrm{v}}\right)$ are responsible for $\mathrm{K}^{+}$ efflux in response to membrane depolarization and have been identified in activated microglia [172]. Microglia stimulated by LPS express the $\mathrm{K}_{\mathrm{v}} 1.5$ channel subtype [183] and a 4-AP-sensitive current has been shown to contribute to the resting membrane potential in LPS-activated microglia [175]. Nitrite production - a marker of microglial activation was reduced by 4-AP as well as by $\mathrm{K}_{\mathrm{v}} 1.5$ knockdown with antisense oligonucleotides, and $\mathrm{K}_{\mathrm{v}} 1.5$ knockout experiments [184]. This suggests that changes in the expression pattern of $\mathrm{K}_{\mathrm{v}} 1.5$ channels may play an important role in the initiation of microglial activation [183].

The $\mathrm{K}_{\mathrm{v}} 1.3$ channel subtype has been cloned from primary cultured microglia using RT-PCR [185]. $\mathrm{K}_{\mathrm{v}} 1.3$ expression levels were modulated by transforming growth factor- $\beta$ and altered in slice culture conditions $[179,186]$. In addition, $\mathrm{K}_{\mathrm{v}} 1.3$ channels in microglia are up-regulated in response to $\mathrm{A} \beta$ peptide, the main constituent of amyloid plaques in the Alzheimer's disease [161]. LPS or L-glutamate can also increase microglial $\mathrm{K}_{\mathrm{v}} 1.3$ expression level; this effect was reduced by application of minocycline, an inhibitor of microglial activation through blockade of p38-MAPK [187].

Both $\mathrm{K}_{\mathrm{v}} 1.5$ and $\mathrm{K}_{\mathrm{v}} 1.3$ are expressed differentially in states of microglial activation; $\mathrm{K}_{\mathrm{v}} 1.5$ expression appears to correlate with a non-proliferating phenotype of microglia in slice culture, whereas expression of the $\mathrm{K}_{\mathrm{v}} 1.3$ channel subtype correlated with microglia proliferation [184]. Furthermore, immunohistochemical data has confirmed that the change in expression from $\mathrm{K}_{\mathrm{v}} 1.5$ to $\mathrm{K}_{\mathrm{v}} 1.3$ was simultaneous to the enhanced proliferation [186]. In a model of facial nerve axotomy, delayed rectifier $\mathrm{K}^{+}$channels were expressed 1 day after injury and remained until 3 days, but were downregulated 7 days after axotomy [134]. Interestingly, the microglial proliferation rate after facial nerve lesion was higher in $\mathrm{K}_{\mathrm{v}} 1.5$ gene knockout animals as compared to wild type [134]. Delayed rectifier $\mathrm{K}^{+}$channels therefore appear to play dynamic and varied roles in the early stages of microglial activation.

\subsubsection{Calcium-Activated Potassium Channels}

The intracellular concentration of $\mathrm{Ca}^{2+}$ can be elevated by influx of extracelluar $\mathrm{Ca}^{2+}$ through ionotropic receptors and channels, or release from intracellular $\mathrm{Ca}^{2+}$ stores. $\mathrm{Ca}^{2+}-$ activated $\mathrm{K}^{+}$channels $\left(\mathrm{K}_{\mathrm{Ca}}\right)$, which are activated by increasing intracellular $\mathrm{Ca}^{2+}$, have been identified in microglia [178]. $\mathrm{K}_{\mathrm{Ca}}$ channels are sub-categorized by their unitary conductance property as large conductance (BK), intermediate conductance (IK) and small conductance (SK) $\mathrm{K}_{\mathrm{Ca}}$ channels.

Microglia exhibit $\mathrm{K}_{\mathrm{Ca}}$ currents in cultured brain slices. The currents showed voltage-dependence, had a large unitary conductance and were inhibited by extracellular tetraethylammonium chloride application [172]. Human microglia in hippocampal slices obtained from the temporal lobe of epilepsy patients express $\mathrm{BK}$ channels $\left(\mathrm{K}_{\mathrm{Ca}} 1.1\right)$, which were shown to be modulated by the chemokine macrophage in- flammatory protein (MIP)-1a [68]. That microglia exhibit $\mathrm{K}_{\mathrm{Ca}}$ currents in cultured brain slices but not in acutely prepared slices [172] suggests that microglia undergo a functional change after long term culture. This finding emphasizes the need to interpret with caution electrophysiology experiments performed under differing conditions.

Expression of IK channels $\left(\mathrm{K}_{\mathrm{Ca}} 3.1\right)$ encoded by the gene $k c a 3.1$ has been reported in cultured microglia. IK channel currents were induced by lysophospholipid via increase in the level of intracellular $\mathrm{Ca}^{2+}$ and were blocked by charybdotoxin [188]. IK channels appear to contribute to microglia activation and nitric oxide-dependent neurodegeneration. Neuronal death and degeneration was markedly reduced using the selective inhibitor of IK channels, triarylmethane-34 (TRAM-34). IK channels could be functionally related to activation of the p38-MAPK pathway, which can induce the release of pro-inflammatory cytokines and chemokines as well as nitric oxide [189].

Several subtypes of SK channel - SK2 $\left(\mathrm{K}_{\mathrm{Ca}} 2.2\right)$ and SK3 $\left(\mathrm{K}_{\mathrm{C} 2} 2.3\right)$ - were identified in microglia using RT-PCR. SK3 channel proteins were detected with specific antibodies and functional expression of the SK2 channel was confirmed using the antagonist apamin [190].

The activity of the various $\mathrm{K}_{\mathrm{Ca}}$ channels expressed in microglia is likely to be driven down-stream either from $\mathrm{Ca}^{2+}$ signaling via metabotropic receptor-activation of $\mathrm{Ca}^{2+}$ stores or activation of $\mathrm{Ca}^{2+}$ permeable ion channels, which as we have described above appear to play a critical role in the mechanisms of microglial activation. $\mathrm{K}_{\mathrm{Ca}}$ channel activity may therefore play an intermediary role between receptor activation and changes in microglial membrane properties.

\section{CONCLUDING REMARKS}

In this review, we have summarized evidence for possible microglia contributions to trigeminal nerve injury, trigeminal neuralgia and migraine. Greater understanding of microglia and their pathological mechanisms may lead us to new concepts in the treatment of trigeminal-specific pain. We propose the trigeminal system as an ideal model to study the properties and behavior of microglia at the interface of sensory signaling. The somatotopic and functional distribution of primary afferent inputs to the trigeminal spinal nucleus [1] allows microglia to be studied at a variety of locations (Sp5C; Sp5I/Sp5C boundary; Sp5O) specific to unique and well-characterized sensory pathways $[62,191]$. It is also possible to ask questions concerning intra- or inter-nuclear signaling [63] and the pathological significance of microglia involvement in its modulation. Such studies may offer clues to potentially multiple roles for microglia in nociceptive modulation, not just in trigeminal but also spinal neuropathic pain.

Even 'at rest', microglia are by no means static and show dynamic activity in the CNS [130]; it therefore follows that microglial properties may change on an equivalently rapid time scale. As we have described, several membrane conductances, including those carried by $\mathrm{K}^{+}$and $\mathrm{Ca}^{2+}$ ions, may underlie the mechanisms of microglial activation. Electrophysiology studies therefore hold promise to measure such changes to microglial membrane properties. Recording microglia in a physiologically 'resting' condition is inevitably 
compromised by the need to dissect microglia from CNS tissue. According to early studies of microglia within brain slices, even acute preparation cannot avoid the activation of microglia at the slice surface [155]. In contrast to the defined activation phenotypes of peripheral macrophage [192], there exists no comprehensive index to distinguish the stages of microglial activation in relation to their microenvironment. However, this may be overcome by the use of experimental conditions relevant to the particular microglia state under study, whether by dissociated culture, acute brain slice or slice culture. Further, advances in microscopy and the use of genetically modified mice [94] should allow the identification of relatively 'resting' microglia deep within brain slices. Future electrophysiological studies of microglial properties may even help to elucidate the characteristics that define their likely varied activation states.

Our knowledge of microglia functions may be greatly enhanced by furthering our understanding of the interactions between neurons and microglia in the normal 'resting' condition, as well as in pathology. Microglia appear to be kept in quiescence by a balance of suppressing factors of neuronal origin [101]. Disturbance to this close physical relationship, either via injury or other neuronal insult, may contribute to microglial pathology. Future studies must again consider microglia together with their immediate environment and partnership with neighboring cells. The opportunity of maintaining microglia in situ can be afforded by the use of brain slice techniques, while at the same time allowing access for recording and pharmacological manipulation.

Equally important to such advances are how the activities of microglia impinge on neuronal properties within the trigeminal brainstem. Changes to synaptic transmission after peripheral nerve injury have been documented in substantia gelatinosa of the spinal dorsal horn [193]. It has further been shown that the consequences of peripheral nerve injury extend to changes in the properties of secondary neurons intrinsic to the superficial dorsal horn; the development of which may involve microglial mechanisms [194]. It remains to be investigated whether similar changes occur to the intrinsic properties of neurons or synaptic transmission within the superficial Sp5C $[117,195]$ after trigeminal nerve injury.

In this age of genetic manipulation, the establishment of experimental protocols in mouse models [35] allows a timely return to questions of trigeminal central sensitization. Conditional gene-knockout or knock-in animals may help to answer fundamental questions about this unique and complex sensory system in health and disease. Furthermore, advances in functional imaging of the trigeminal nuclei in humans [196] offer a unique opportunity to correlate promising pharmacological therapies with physiological readouts in neuropathic pain patients.

\section{ACKNOWLEDGMENTS}

This work was supported by Grant (R0A-2008-00020101-0) from National Research Laboratory Program and Grant (20090086663) from the Basic Research Program funded by the Ministry of Education, Science and Technology, the Republic of Korea, as well as by an International Travel Grant (TG080169) from the Royal Society, UK.

\section{ABBREVIATIONS}

\begin{tabular}{|c|c|c|}
\hline 4-AP & $=$ & 4-aminopyridine \\
\hline $\mathrm{ACM}$ & $=$ & astrocyte-conditioned medium \\
\hline ATF-3 & $=$ & activating transcription factor-3 \\
\hline ATP & $=$ & adenosine 5'-triphosphate \\
\hline $\mathrm{A} \beta$ & $=$ & amyloid $\beta$ peptide \\
\hline $\mathrm{BDNF}$ & $=$ & brain-derived neurotrophic factor \\
\hline BK & $=$ & $\begin{array}{l}\text { large conductance calcium-activated potas- } \\
\text { sium channel }\end{array}$ \\
\hline BrdU & $=$ & bromodeoxyuridine \\
\hline $\mathrm{CCI}$ & $=$ & chronic constriction injury \\
\hline CD11b & $=$ & cluster of differentiation molecule $11 \mathrm{~b}$ \\
\hline CGA & $=$ & chromogranin A \\
\hline CGRP & $=$ & calcitonin gene-related peptide \\
\hline CHPG & $=$ & (RS)-2-chloro-5-hydroxyphenlglycine \\
\hline CNS & $=$ & central nervous system \\
\hline $\mathrm{COX}$ & $=$ & cyclooxygenase \\
\hline CX3CR1 & $=$ & fractalkine receptor \\
\hline ERK & $=$ & extracellular signal-related kinase \\
\hline GABA & $=$ & gamma-aminobutyric acid \\
\hline GFAP & $=$ & glial fibrillary acidic protein \\
\hline GS & $=$ & glutamine synthetase \\
\hline HSV & $=$ & herpes simplex virus \\
\hline IAN & $=$ & inferior alveolar nerve \\
\hline IB4 & $=$ & isolectin B4 \\
\hline Iba-1 & $=$ & ionized calcium binding adaptor molecule- 1 \\
\hline IFN- $\gamma$ & $=$ & interferon-gamma \\
\hline IK & $=$ & $\begin{array}{l}\text { intermediate conductance calcium- } \\
\text { activated potassium channel }\end{array}$ \\
\hline IL & $=$ & interleukin \\
\hline ION & $=$ & infraorbital nerve \\
\hline $\mathrm{K}_{\mathrm{Ca}}$ & $=$ & calcium-activated potassium channel \\
\hline $\mathrm{K}_{\mathrm{ir}}$ & $=$ & inward rectifier potassium channel \\
\hline $\mathrm{K}_{\mathrm{v}}$ & $=$ & delayed rectifier potassium channel \\
\hline LC1 & $=$ & lipocortin-1 \\
\hline LPS & $=$ & lipopolysaccharide \\
\hline LTP & $=$ & long term potentiation \\
\hline MAPK & $=$ & mitogen activated protein kinase \\
\hline mGluR & $=$ & metabotropic glutamate receptor \\
\hline MHC & $=$ & major histocompatability complex \\
\hline MIP-1 $1 \alpha$ & $=$ & macrophage inflammatory protein-1 alpha \\
\hline NK-1 & $=$ & neurokinin-1 \\
\hline NMDA & $=$ & N-methyl-D-aspartic acid \\
\hline NO & $=$ & nitric oxide \\
\hline
\end{tabular}




\begin{tabular}{|c|c|c|}
\hline $\mathrm{P} 2 \mathrm{X}$ & $=$ & ionotropic purinergic receptor channel \\
\hline PDGF & $=$ & platelet-derived growth factor \\
\hline $\mathrm{PGE}_{2}$ & $=$ & prostaglandin $\mathrm{E}_{2}$ \\
\hline $\mathrm{PKC}$ & $=$ & protein kinase $\mathrm{C}$ \\
\hline PLC & $=$ & phospholipase C \\
\hline RT-PCR & $=$ & $\begin{array}{l}\text { reverse transcription polymerase chain } \\
\text { reaction }\end{array}$ \\
\hline sFNK & $=$ & soluble form of fractalkine \\
\hline SK & $=$ & $\begin{array}{l}\text { small conductance calcium-activated } \\
\text { channel }\end{array}$ \\
\hline Sp5 & $=$ & spinal nucleus of trigeminal nerve \\
\hline Sp5C & $=$ & trigeminal subnucleus caudalis \\
\hline Sp5I & $=$ & trigeminal subnucleus interpolaris \\
\hline $\mathrm{Sp} 5 \mathrm{O}$ & $=$ & trigeminal subnucleus oralis \\
\hline $\mathrm{TNF}-\alpha$ & $=$ & tumor necrosis factor-alpha \\
\hline TRAM-34 & & triarylmethane-34 \\
\hline TUNEL & $=$ & terminal dUTP nick end labeling \\
\hline
\end{tabular}

[1] Sessle BJ. Acute and chronic craniofacial pain: brainstem mechanisms of nociceptive transmission and neuroplasticity, and their clinical correlates. Crit Rev Oral Biol Med 2000; 11: 57-91.

[2] Elias WJ, Burchiel KJ. Trigeminal neuralgia and other neuropathic pain syndromes of the head and face. Curr Pain Headache Rep 2002; 6: 115-24.

[3] Fried K, Lillesaar C, Sime W, Kaukua N, Patarroyo M. Target finding of pain nerve fibers: neural growth mechanisms in the tooth pulp. Physiol Behav 2007; 92: 40-45.

[4] Meng ID, Bereiter DA. Differential distribution of Fos-like immunoreactivity in the spinal trigeminal nucleus after noxious and innocuous thermal and chemical stimulation of rat cornea. Neuroscience 1996; 72: 243-54.

[5] Bolton S, O'Shaughnessy CT, Goadsby PJ. Properties of neurons in the trigeminal nucleus caudalis responding to noxious dural and facial stimulation. Brain Res 2005; 1046: 122-29.

[6] Bereiter DA, Hirata H, Hu JW. Trigeminal subnucleus caudalis: beyond homologies with the spinal dorsal horn. Pain 2000;88: 221-24.

[7] Wallace JM. Update on pharmacotherapy guidelines for treatment of neuropathic pain. Curr Pain Headache Rep 2007; 11: 208-14.

[8] Rauck RL, Wallace MS, Burton AW, Kapural L, North JM. Intrathecal ziconotide for neuropathic pain: a review. Pain Pract 2009; 9: 327-37.

[9] Pietrobon D, Striessnig J. Neurobiology of migraine. Nat Rev Neurosci $2003 ; 4$ : 386-98

[10] Cruccu G, Gronseth G, Alksne J, et al. AAN-EFNS guidelines on trigeminal neuralgia management. Eur J Neurol 2008; 15: 1013-28.

[11] Bussone G, Franzini A, Proietti A, et al. Deep brain stimulation in craniofacial pain: seven years' experience. Neurol Sci 2007; 28 (Suppl 2): S146-49.

[12] Sicher H. Oral Anatomy. 3rd ed. St. Louis: C. V. Mosby Co.; 1960.

[13] Hirata H, Okamoto K, Tashiro A, Bereiter DA. A novel class of neurons at the trigeminal subnucleus interpolaris/caudalis transition region monitors ocular surface fluid status and modulates tear production. J Neurosci 2004; 24: 4224-32.

[14] DaSilva AF, Becerra L, Makris N, et al. Somatotopic activation in the human trigeminal pain pathway. J Neurosci 2002; 22: 8183-92.

[15] Wang H, Wei F, Dubner R, Ren K. Selective distribution and function of primary afferent nociceptive inputs from deep muscle tissue to the brainstem trigeminal transition zone. J Comp Neurol 2006; 498: 390-402.

[16] Gerard MEW. Afferent impulses of the trigeminal nerve: the intramedullary course of the painful, thermal and tactile impulses. Arch Neurol Psychiat 1923; 9: 306-38.
[17]
Kerr FW. The fine structure of the subnucleus caudalis of the trigeminal nerve. Brain Res 1970; 23: 129-45.

Sugimoto T, Fujiyoshi Y, Xiao C, He YF, Ichikawa H. Central projection of calcitonin gene-related peptide (CGRP)- and substance $\mathrm{P}$ (SP)-immunoreactive trigeminal primary neurons in the rat. $\mathrm{J}$ Comp Neurol 1997; 378: 425-42.

Olszewski J. On the anatomical and functional organization of the spinal trigeminal nucleus. J Comp Neurol 1950; 92: 401-13.

Rexed B. The cytoarchitectonic organization of the spinal cord in the cat. J Comp Neurol 1952; 96: 414-95.

Melzack R, Wall PD. Pain mechanisms: a new theory. Science 1965; 150: 971-79.

Willis WD, Coggeshall RE. Sensory mechanisms of the spinal cord. New York; London: Kluwer Academic/Plenum 2004.

Ambalavanar R, Morris R. The distribution of binding by isolectin I-B4 from Griffonia simplicifolia in the trigeminal ganglion and brainstem trigeminal nuclei in the rat. Neuroscience 1992; 47: 42129.

Sugimoto T, Fujiyoshi Y, He YF, Xiao C, Ichikawa H. Trigeminal primary projection to the rat brain stem sensory trigeminal nuclear complex and surrounding structures revealed by anterograde transport of cholera toxin B subunit-conjugated and Bandeiraea simplicifolia isolectin B4-conjugated horseradish peroxidase. Neurosci Res 1997; 28: 361-71.

Sjöqvist O. Studies on pain conduction in the trigeminal nerve: A contribution to the surgical treatment of facial pain. Acta Psychiat Neurol Scand 1938; (Suppl XVII): 1-139.

Pajot J, Pelissier T, Sierralta F, Raboisson P, Dallel R. Differential effects of trigeminal tractotomy on Adelta- and C-fiber-mediated nociceptive responses. Brain Res 2000; 863: 289-92.

McMahon SB, Priestley JV. Nociceptor plasticity. In: Hunt S, Koltzenburg M eds, The Neurobiology of Pain. Oxford: Oxford University Press 2005: 35-64.

Henry MA, Nousek-Goebl NA, Westrum LE. Light and electron microscopic localization of calcitonin gene-related peptide immunoreactivity in lamina II of the feline trigeminal pars caudalis/medullary dorsal horn: a qualitative study. Synapse 1993; 13: 99-107.

Tal M, Devor M. Ectopic discharge in injured nerves: comparison of trigeminal and somatic afferents. Brain Res 1992; 579: 148-51.

Benoliel R, Eliav E, Tal M. No sympathetic nerve sprouting in rat trigeminal ganglion following painful and non-painful infraorbital nerve neuropathy. Neurosci Lett 2001; 297: 151-54.

Bongenhielm U, Boissonade FM, Westermark A, Robinson PP, Fried K. Sympathetic nerve sprouting fails to occur in the trigeminal ganglion after peripheral nerve injury in the rat. Pain 1999; 82: 283-88.

32] Juhl GI, Jensen TS, Norholt SE, Svensson P. Central sensitization phenomena after third molar surgery: a quantitative sensory testing study. Eur J Pain 2008; 12: 116-27.

] Piao ZG, Cho IH, Park CK, et al. Activation of glia and microglial p38 MAPK in medullary dorsal horn contributes to tactile hypersensitivity following trigeminal sensory nerve injury. Pain 2006; 121: $219-31$.

Saito K, Hitomi S, Suzuki I, et al. Modulation of trigeminal spina subnucleus caudalis neuronal activity following regeneration of transected inferior alveolar nerve in rats. J Neurophysiol 2008; 99: 2251-63.

35] Xu M, Aita M, Chavkin C. Partial infraorbital nerve ligation as a model of trigeminal nerve Injury in the mouse: behavioral, neural, and glial reactions. J Pain 2008; 9(11): 1036-48.

Eriksson NP, Persson JK, Svensson M, et al. A quantitative analysis of the microglial cell reaction in central primary sensory projection territories following peripheral nerve injury in the adult rat. Exp Brain Res 1993; 96: 19-27.

Melzer P, Zhang MZ, McKanna JA. Infraorbital nerve transection and whisker follicle removal in adult rats affect microglia and astrocytes in the trigeminal brainstem. A study with lipocortin1- and S100beta-immunohistochemistry. Neuroscience 1997; 80: 459-72. Jacquin MF, Semba K, Egger MD, Rhoades RW. Organization of HRP-labeled trigeminal mandibular primary afferent neurons in the rat. J Comp Neurol 1983; 215: 397-20.

Marfurt CF. The central projections of trigeminal primary afferent neurons in the cat as determined by the tranganglionic transport of horseradish peroxidase. J Comp Neurol 1981; 203: 785-98. 
[40] Wei F, Guo W, Zou S, Ren K, Dubner R. Supraspinal glialneuronal interactions contribute to descending pain facilitation. J Neurosci 2008; 28: 10482-95.

[41] Lim EJ, Jeon HJ, Yang GY, et al. Intracisternal administration of mitogen-activated protein kinase inhibitors reduced mechanical allodynia following chronic constriction injury of infraorbital nerve in rats. Prog Neuropsychopharmacol Biol Psychiatry 2007; 31: 1322-29.

[42] Goadsby PJ. The vascular theory of migraine-a great story wrecked by the facts. Brain 2009; 132: 6-7.

[43] Burstein R, Yamamura H, Malick A, Strassman AM. Chemical stimulation of the intracranial dura induces enhanced responses to facial stimulation in brain stem trigeminal neurons. J Neurophysiol 1998; 79: 964-82.

[44] Jakubowski M, Levy D, Goor-Aryeh I, et al. Terminating migraine with allodynia and ongoing central sensitization using parenteral administration of COX1/COX2 inhibitors. Headache 2005; 45 : 850-61.

[45] Tomimoto H, Shibata M, Ihara M, et al. A comparative study on the expression of cyclooxygenase and 5-lipoxygenase during cerebral ischemia in humans. Acta Neuropathol 2002; 104: 601-07.

[46] Tanaka S, Nakamura T, Sumitani K, et al. Stage- and regionspecific cyclooxygenase expression and effects of a selective COX1 inhibitor in the mouse amygdala kindling model. Neurosci Res 2009; 65: 79-87.

[47] Schwab JM, Brechtel K, Nguyen TD, Schluesener HJ. Persistent accumulation of cyclooxygenase-1 (COX-1) expressing microgli$\mathrm{a} / \mathrm{macrophages}$ and upregulation by endothelium following spinal cord injury. J Neuroimmunol 2000; 111: 122-30.

[48] Bartley J. Could glial activation be a factor in migraine? Med Hypotheses 2009; 72: 255-57.

[49] Hutchinson MR, Northcutt AL, Chao LW, et al. Minocycline suppresses morphine-induced respiratory depression, suppresses morphine-induced reward, and enhances systemic morphine-induced analgesia. Brain Behav Immun 2008; 22(8):1248-56.

[50] Raghavendra V, Rutkowski MD, DeLeo JA. The role of spinal neuroimmune activation in morphine tolerance/hyperalgesia in neuropathic and sham-operated rats. J Neurosci 2002; 22: 9980-89.

[51] Horvath RJ, DeLeo JA. Morphine enhances microglial migration through modulation of P2X4 receptor signaling. J Neurosci 2009; 29: 998-1005.

[52] Nurmikko TJ. Pathophysiology of MS-related trigeminal neuralgia. Pain 2009; 143: 165-66.

[53] Cruccu G, Biasiotta A, Di Rezze S, et al. Trigeminal neuralgia and pain related to multiple sclerosis. Pain 2009; 143: 186-91.

[54] Napoli I, Neumann H. Protective effects of microglia in multiple sclerosis. Exp Neurol 2009.; dói: 10.1016/j.expneurol.2009. 04.024

[55] Zhang Z, Zhang ZY, Fauser U, Schluesener HJ. Mechanical allodynia and spinal up-regulation of $\mathrm{P} 2 \mathrm{X} 4$ receptor in experimental autoimmune neuritis rats. Neuroscience 2008; 152: 495-501.

[56] Yeo JF, Liu HP, Leong SK. Sustained microglial immunoreactivity in the caudal spinal trigeminal nucleus after formalin injection. $\mathrm{J}$ Dent Res 2001; 80: 1524-29.

[57] Xie YF, Zhang S, Chiang CY, et al. Involvement of glia in central sensitization in trigeminal subnucleus caudalis (medullary dorsal horn). Brain Behav Immunol 2007; 21: 634-41.

[58] Xie YF. Glial involvement in trigeminal central sensitization. Acta Pharmacol Sin 2008; 29: 641-45.

[59] Dong H, Tian YK, Xiang HB, Tian XB, Jin XG. [The cellular location and significance of p38alpha/beta isoforms in the lumbar spinal cord of the bone cancer pain rats]. Zhonghua Yi Xue Za Zhi 2007; 87: 53-57.

[60] Korb A, Tohidast-Akrad M, Cetin E, et al. Differential tissue expression and activation of p38 MAPK alpha, beta, gamma, and delta isoforms in rheumatoid arthritis. Arthritis Rheum 2006; 54: 2745-56.

[61] Guo W, Wang H, Watanabe M, et al. Glial-cytokine-neuronal interactions underlying the mechanisms of persistent pain. J Neurosci 2007; 27: 6006-18.

[62] Dubner R, Ren K. Brainstem mechanisms of persistent pain following injury. J Orofac Pain 2004; 18: 299-305.

[63] Han SM, Ahn DK, Youn DH. Pharmacological analysis of excitatory and inhibitory synaptic transmission in horizontal brainstem slices preserving three subnuclei of spinal trigeminal nucleus. J Neurosci Methods 2008; 167: 221-28.
[64] Ren K, Dubner R. Neuron-glia crosstalk gets serious: role in pain hypersensitivity. Curr Opin Anaesthesiol 2008; 21: 570-79.

[65] Yihong Z, Tamada Y, Akai K, Suwa F. Morphological interrelationship between astrocytes and nerve endings in the rat spinal trigeminal nucleus caudalis. Okajimas Folia Anat Jpn 2006; 83: 9196.

[66] Verkhratsky A, Kirchhoff F. Glutamate-mediated neuronal-glial transmission. J Anat 2007; 210: 651-60.

[67] Chiang CY, Wang J, Xie YF, et al. Astroglial glutamate-glutamine shuttle is involved in central sensitization of nociceptive neurons in rat medullary dorsal horn. J Neurosci 2007; 27: 9068-76.

[68] Bordey A, Spencer DD. Chemokine modulation of highconductance $\mathrm{Ca}(2+)$-sensitive $\mathrm{K}(+)$ currents in microglia from human hippocampi. Euro J Neurosci 2003; 18: 2893-98.

[69] Dubner R. Plasticity in central nociceptive pathways. In: Merskey H, Loeser JD, Dubner R, Eds. The paths of pain, 1975-2005. Seattle: IASP Press 2005; 101-15.

[70] Bereiter DA, Hathaway CB, Benetti AP. Caudal portions of the spinal trigeminal complex are necessary for autonomic responses and display Fos-like immunoreactivity after corneal stimulation in the cat. Brain Res 1994; 657: 73-82.

[71] Dallel R, Duale C, Molat JL. Morphine administered in the substantia gelatinosa of the spinal trigeminal nucleus caudalis inhibits nociceptive activities in the spinal trigeminal nucleus oralis. $\mathrm{J} \mathrm{Neu}-$ rosci 1998; 18: 3529-36.

[72] Hu B, Chiang CY, Hu JW, Dostrovsky JO, Sessle BJ. P2X receptors in trigeminal subnucleus caudalis modulate central sensitization in trigeminal subnucleus oralis. J Neurophysiol 2002; 88: 161424.

[73] Park SJ, Zhang S, Chiang CY, et al. Central sensitization induced in thalamic nociceptive neurons by tooth pulp stimulation is dependent on the functional integrity of trigeminal brainstem subnucleus caudalis but not subnucleus oralis. Brain Res 2006; 1112: 134-45.

[74] Seo K, Fujiwara N, Takeuchi K, Maeda T, Someya G. Postnatal development of excitation propagation in the trigeminal subnucleus caudalis evoked by afferent stimulation in mice. Neurosci Res 2005; 52: 201-10.

[75] Chiang CY, Zhang S, Xie YF, et al. Endogenous ATP involvement in mustard-oil-induced central sensitization in trigeminal subnucleus caudalis (medullary dorsal horn). J Neurophysiol 2005; 94 : 1751-60.

[76] Hathway GJ, Vega-Avelaira D, Moss A, Ingram R, Fitzgerald M. Brief, low frequency stimulation of rat peripheral C-fibres evokes prolonged microglial-induced central sensitization in adults but not in neonates. Pain 2009; 144: 110-18.

[77] Wen YR, Suter MR, Kawasaki Y, et al. Nerve conduction blockade in the sciatic nerve prevents but does not reverse the activation of p38 mitogen-activated protein kinase in spinal microglia in the rat spared nerve injury model. Anesthesiology 2007; 107: 312-21.

[78] Coull JA, Beggs S, Boudreau D, et al. BDNF from microglia causes the shift in neuronal anion gradient underlying neuropathic pain. Nature 2005; 438: 1017-21.

[79] Kim D, Kim MA, Cho IH, et al. A critical role of toll-like receptor 2 in nerve injury-induced spinal cord glial cell activation and pain hypersensitivity. J Biol Chem 2007; 282: 14975-983.

[80] Karp HL, Tillotson ML, Soria J, Reich C, Wood JG. Microglial tyrosine phosphorylation systems in normal and degenerating brain. Glia 1994; 11: 284-90.

[81] Griffith R, Soria J, Wood JG. Regulation of microglial tyrosine phosphorylation in response to neuronal injury. Exp Neurol 2000; 161: 297-305.

[82] Mori I, Goshima F, Koshizuka T, et al. Iba1-expressing microglia respond to herpes simplex virus infection in the mouse trigeminal ganglion. Brain Res Mol Brain Res 2003; 120: 52-56.

[83] Westrum LE, Black RG. Changes in the synapses of the spinal trigeminal nucleus after ipsilateral rhizotomy. Brain Res 1968; 11: 706-9.

[84] Arvidsson J. An ultrastructural study of transganglionic degeneration in the main sensory trigeminal nucleus of the rat. J Neurocytol 1979; 8: 31-45.

[85] Beggs S, Salter MW. Stereological and somatotopic analysis of the spinal microglial response to peripheral nerve injury. Brain Behav Immun 2007; 21: 624-33.

[86] Waite PM. Rearrangement of neuronal responses in the trigeminal system of the rat following peripheral nerve section. J Physiol 1984; 352: 425-45. 
[87] Woolf CJ, Shortland P, Coggeshall RE. Peripheral nerve injury triggers central sprouting of myelinated afferents. Nature 1992; 355: 75-78.

[88] Mannion RJ, Doubell TP, Coggeshall RE, Woolf CJ. Collateral sprouting of uninjured primary afferent A-fibers into the superficial dorsal horn of the adult rat spinal cord after topical capsaicin treatment to the sciatic nerve. J Neurosci 1996; 16: 5189-95.

[89] De Riu PL, Russo A, Pellitteri R, et al. Primary afferent plasticity following deafferentation of the trigeminal brainstem nuclei in the adult rat. Exp Neurol 2008; 213: 101-7.

[90] Noda M, Nakanishi H, Nabekura J, Akaike N. AMPA-kainate subtypes of glutamate receptor in rat cerebral microglia. J Neurosci 2000; 20: 251-58.

[91] Matsuka Y, Ono T, Iwase H, et al. Altered ATP release and metabolism in dorsal root ganglia of neuropathic rats. Mol Pain 2008; 4 : 66.

[92] Masuda J, Tsuda M, Tozaki-Saitoh H, Inoue K. Intrathecal delivery of PDGF produces tactile allodynia through its receptors in spinal microglia. Mol Pain 2009; 5: 23.

[93] Marriott I. The role of tachykinins in central nervous system inflammatory responses. Front Biosci 2004; 9: 2153-65.

[94] Jung S, Aliberti J, Graemmel P, et al. Analysis of fractalkine receptor $\mathrm{CX}(3) \mathrm{CR} 1$ function by targeted deletion and green fluorescent protein reporter gene insertion. Mol Cell Biol 2000; 20: 4106-14.

[95] Maciejewski-Lenoir D, Chen S, Feng L, Maki R, Bacon KB. Characterization of fractalkine in rat brain cells: migratory and activation signals for CX3CR-1-expressing microglia. J Immunol 1999; 163: $1628-35$

[96] Harrison JK, Jiang Y, Chen S, et al. Role for neuronally derived fractalkine in mediating interactions between neurons and CX3CR1-expressing microglia. Proc Natl Acad Sci USA 1998; 95 : 10896-901.

[97] Milligan E, Zapata V, Schoeniger D, et al. An initial investigation of spinal mechanisms underlying pain enhancement induced by fractalkine, a neuronally released chemokine. Eur J Neurosci 2005; 22: $2775-82$

[98] Clark AK, Yip PK, Malcangio M. The liberation of fractalkine in the dorsal horn requires microglial cathepsin S. J Neurosci 2009; 29: 6945-54.

[99] Lyons A, Lynch AM, Downer EJ, et al. Fractalkine-induced activation of the phosphatidylinositol-3 kinase pathway attentuates microglial activation in vivo and in vitro. J Neurochem 2009; 110: 1547-56.

[100] Lyons A, Downer EJ, Crotty S, et al. CD200 ligand receptor interaction modulates microglial activation in vivo and in vitro: a role for IL-4. J Neurosci 2007; 27: 8309-13.

[101] Lynch MA. The multifaceted profile of activated microglia. Mol Neurobiol 2009; 40: 139-56.

[102] Fried K, Bongenhielm U, Boissonade FM, Robinson PP. Nerve injury-induced pain in the trigeminal system. Neuroscientist 2001; 7: $155-65$.

[103] Goadsby PJ. Calcitonin gene-related peptide antagonists as treatments of migraine and other primary headaches. Drugs 2005; 65: 2557-67.

[104] Goadsby PJ, Edvinsson L, Ekman R. Vasoactive peptide release in the extracerebral circulation of humans during migraine headache. Ann Neurol 1990; 28: 183-87.

[105] Tepper SJ, Cleves C. Telcagepant, a calcitonin gene-related peptide antagonist for the treatment of migraine. Curr Opin Investig Drugs 2009; 10: 711-20.

[106] Capuano A, De Corato A, Lisi L, et al. Proinflammatory-activated trigeminal satellite cells promote neuronal sensitization: relevance for migraine pathology. Mol Pain 2009; 5: 43.

[107] Li J, Vause CV, Durham PL. Calcitonin gene-related peptide stimulation of nitric oxide synthesis and release from trigeminal ganglion glial cells. Brain Res 2008; 1196: 22-32.

[108] Takeda M, Tanimoto T, Kadoi J, et al. Enhanced excitability of nociceptive trigeminal ganglion neurons by satellite glial cytokine following peripheral inflammation. Pain 2007; 129: 155-66.

[109] Ceruti S, Fumagalli M, Villa G, Verderio C, Abbracchio MP. Purinoceptor-mediated calcium signaling in primary neuron-glia trigeminal cultures. Cell Calcium 2008; 43: 576-90.

[110] Ruan HZ, Moules E, Burnstock G. Changes in P2X3 purinoceptors in sensory ganglia of the mouse during embryonic and postnatal development. Histochem Cell Biol 2004; 122: 539-51.
[111] Vulchanova L, Riedl MS, Shuster SJ, et al. P2X3 is expressed by DRG neurons that terminate in inner lamina II. Eur J Neurosci 1998; 10: 3470-78.

[112] Staikopoulos V, Sessle BJ, Furness JB, Jennings EA. Localization of $\mathrm{P} 2 \mathrm{X} 2$ and $\mathrm{P} 2 \mathrm{X} 3$ receptors in rat trigeminal ganglion neurons. Neuroscience 2007; 144: 208-16.

[113] Ambalavanar R, Moritani M, Dessem D. Trigeminal P2X3 receptor expression differs from dorsal root ganglion and is modulated by deep tissue inflammation. Pain 2005; 117: 280-91.

[114] Fabbretti E, D'Arco M, Fabbro A, et al. Delayed upregulation of ATP P2X3 receptors of trigeminal sensory neurons by calcitonin gene-related peptide. J Neurosci 2006; 26: 6163-71.

[115] Eriksson J, Bongenhielm U, Kidd E, Matthews B, Fried K. Distribution of $\mathrm{P} 2 \mathrm{X} 3$ receptors in the rat trigeminal ganglion after inferior alveolar nerve injury. Neurosci Lett 1998; 254: 37-40.

[116] Shinoda M, Kawashima K, Ozaki N, et al. P2X3 receptor mediates heat hyperalgesia in a rat model of trigeminal neuropathic pain. $\mathrm{J}$ Pain 2007; 8: 588-97.

[117] Davies AJ, North RA. Electrophysiological and morphological properties of neurons in the substantia gelatinosa of the mouse trigeminal subnucleus caudalis. Pain 2009; 146: 214-21.

[118] Fields RD, Burnstock G. Purinergic signalling in neuron-glia interactions. Nat Rev Neurosci 2006; 7: 423-36.

[119] Kato F, Imura T, Shigetomi E. [Purinergic regulatory complex in the brain synapses]. Nihon Shinkei Seishin Yakurigaku Zasshi 2007; 27: 117-26.

[120] Latremoliere A, Mauborgne A, Masson J, et al. Differential implication of proinflammatory cytokine interleukin-6 in the development of cephalic versus extracephalic neuropathic pain in rats. $J$ Neurosci 2008; 28: 8489-501.

[121] Binshtok AM, Wang H, Zimmermann K, et al. Nociceptors are interleukin-1beta sensors. J Neurosci 2008; 28: 14062-73.

[122] Tsuda M, Masuda T, Kitano J, et al. IFN-gamma receptor signaling mediates spinal microglia activation driving neuropathic pain. Proc Natl Acad Sci USA 2009; 106: 8032-37.

[123] Ulmann L, Hatcher JP, Hughes JP, et al. Up-regulation of P2X4 receptors in spinal microglia after peripheral nerve injury mediates BDNF release and neuropathic pain. J Neurosci 2008; 28: 11263 68.

[124] Svensson M, Eriksson NP, Aldskogius H. Evidence for activation of astrocytes via reactive microglial cells following hypoglossal nerve transection. J Neurosci Res 1993; 35: 373-81.

[125] Kawasaki Y, Zhang L, Cheng JK, Ji RR. Cytokine mechanisms of central sensitization: distinct and overlapping role of interleukin1 beta, interleukin-6, and tumor necrosis factor-alpha in regulating synaptic and neuronal activity in the superficial spinal cord. J Neurosci 2008; 28: 5189-94.

[126] Tsuda M, Shigemoto-Mogami Y, Koizumi S, et al. P2X4 receptors induced in spinal microglia gate tactile allodynia after nerve injury. Nature 2003; 424: 778-83.

[127] Gao YJ, Zhang L, Samad OA, et al. JNK-induced MCP-1 production in spinal cord astrocytes contributes to central sensitization and neuropathic pain. J Neurosci 2009; 29: 4096-108.

[128] Thomas WE. Brain macrophages: evaluation of microglia and their functions. Brain Res 1992; 17: 61-74.

[129] Hickey WF. Basic principles of immunological surveillance of the normal central nervous system. Glia 2001; 36: 118-24.

[130] Davalos D, Grutzendler J, Yang G, et al. ATP mediates rapid microglial response to local brain injury in vivo. Nat Neurosci 2005 8: 752-58.

[131] Kreutzberg GW. Microglia: a sensor for pathological events in the CNS. Trends Neurosci 1996; 19: 312-18.

[132] Bruce-Keller AJ. Microglial-neuronal interactions in synaptic damage and recovery. J Neurosci Res 1999; 58: 191-201.

[133] Gonzalez-Scarano F, Baltuch G. Microglia as mediators of inflammatory and degenerative diseases. Annu Rev Neurosci 1999; 22: 219-40.

[134] Boucsein C, Kettenmann H, Nolte C. Electrophysiological properties of microglial cells in normal and pathologic rat brain slices. Euro J Neurosci 2000; 12: 2049-58.

[135] Hoek RM, Ruuls SR, Murphy CA, et al. Down-regulation of the macrophage lineage through interaction with OX2 (CD200). Science 2000; 290: 1768-71

[136] Ohsawa K, Imai Y, Kanazawa H, Sasaki Y, Kohsaka S. Involvement of Iba1 in membrane ruffling and phagocytosis of macrophages/microglia. J Cell Sci 2000; 113 ( Pt 17): 3073-84. 
[137] Postler E, Rimner A, Beschorner R, Schluesener HJ, Meyermann R. Allograft-inflammatory-factor-1 is upregulated in microglial cells in human cerebral infarctions. J Neuroimmunol 2000; 104: 8591.

[138] Autieri MV, Agrawal N. IRT-1, a novel interferon-gammaresponsive transcript encoding a growth-suppressing basic leucine zipper protein. J Biol Chem 1998; 273: 14731-37.

[139] Biber K, Laurie DJ, Berthele A, et al. Expression and signaling of group I metabotropic glutamate receptors in astrocytes and microglia. J Neurochem 1999; 72: 1671-80.

[140] Zhang L, McLarnon JG, Goghari V, et al. Cholinergic agonists increase intracellular $\mathrm{Ca} 2+$ in cultured human microglia. Neurosci Lett 1998; 255: 33-36.

[141] Bader MF, Taupenot L, Ulrich G, Aunis D, Ciesielski-Treska J. Bacterial endotoxin induces $[\mathrm{Ca} 2+]$ i transients and changes the organization of actin in microglia. Glia 1994; 11: 336-44.

[142] Inoue K. Purinergic systems in microglia. Cell Mol Life Sci 2008; 65: 3074-80.

[143] Hegg CC, Hu S, Peterson PK, Thayer SA. Beta-chemokines and human immunodeficiency virus type-1 proteins evoke intracellular calcium increases in human microglia. Neuroscience 2000; 98 : 191-99.

[144] Scholz J, Woolf CJ. The neuropathic pain triad: neurons, immune cells and glia. Nat Neurosci 2007; 10: 1361-68.

[145] D'Aversa TG, Yu KO, Berman JW. Expression of chemokines by human fetal microglia after treatment with the human immunodeficiency virus type 1 protein Tat. J Neurovirol 2004; 10: 86-97.

[146] Nakamura Y, Si QS, Kataoka K. Lipopolysaccharide-induced microglial activation in culture: temporal profiles of morphological change and release of cytokines and nitric oxide. Neurosci Res 1999; 35: 95-100.

[147] Chauvet N, Palin K, Verrier D, et al. Rat microglial cells secrete predominantly the precursor of interleukin-1beta in response to lipopolysaccharide. Eur J Neurosci 2001; 14: 609-17.

[148] Pocock JM, Kettenmann H. Neurotransmitter receptors on microglia. Trends Neurosci 2007; 30: 527-35.

[149] Byrnes KR, Stoica B, Riccio A, et al. Activation of metabotropic glutamate receptor 5 improves recovery after spinal cord injury in rodents. Ann Neurol 2009; 66: 63-74.

[150] Byrnes KR, Stoica B, Loane DJ, et al. Metabotropic glutamate receptor 5 activation inhibits microglial associated inflammation and neurotoxicity. Glia 2009; 57: 550-60.

[151] Loane DJ, Stoica BA, Pajoohesh-Ganji A, Byrnes KR, Faden AI. Activation of metabotropic glutamate receptor 5 modulates microglial reactivity and neurotoxicity by inhibiting NADPH oxidase. J Biol Chem 2009; 284: 15629-39.

[152] Taylor DL, Diemel LT, Cuzner ML, Pocock JM. Activation of group II metabotropic glutamate receptors underlies microglial reactivity and neurotoxicity following stimulation with chromogranin A, a peptide up-regulated in Alzheimer's disease. J Neurochem 2002; 82: 1179-91.

[153] Taylor DL, Diemel LT, Pocock JM. Activation of microglial group III metabotropic glutamate receptors protects neurons against microglial neurotoxicity. J Neurosci 2003; 23: 2150-60.

[154] Ilschner S, Ohlemeyer C, Gimpl G, Kettenmann H. Modulation of potassium currents in cultured murine microglial cells by receptor activation and intracellular pathways. Neuroscience 1995; 66: 9831000.

[155] Brockhaus J, Ilschner S, Banati RB, Kettenmann H. Membrane properties of ameboid microglial cells in the corpus callosum slice from early postnatal mice. J Neurosci 1993; 13: 4412-21.

[156] Draheim HJ, Prinz M, Weber JR, et al. Induction of potassium channels in mouse brain microglia: cells acquire responsiveness to pneumococcal cell wall components during late development. Neuroscience 1999; 89: 1379-90.

[157] Kettenmann H, Hoppe D, Gottmann K, Banati R, Kreutzberg G. Cultured microglial cells have a distinct pattern of membrane channels different from peritoneal macrophages. J Neurosci Res 1990; 26: 278-87.

[158] Eder C. Ion channels in microglia (brain macrophages). Am J Physiol 1998; 275: C327-42.

[159] Boucsein C, Zacharias R, Farber K, et al. Purinergic receptors on microglial cells: functional expression in acute brain slices and modulation of microglial activation in vitro. Eur J Neurosci 2003; 17: 2267-76.
[160] Kuhn SA, van Landeghem FK, Zacharias R, et al. Microglia express $\mathrm{GABA}(\mathrm{B})$ receptors to modulate interleukin release. Mol Cell Neurosci 2004; 25: 312-22.

[161] Franciosi S, Ryu JK, Choi HB, et al. Broad-spectrum effects of 4aminopyridine to modulate amyloid beta1-42-induced cell signaling and functional responses in human microglia. J Neurosci 2006; 26: 11652-64.

[162] North RA. Molecular physiology of P2X receptors. Physiol Rev 2002; 82: 1013-67.

[163] Chessell IP, Hatcher JP, Bountra C, et al. Disruption of the P2X7 purinoceptor gene abolishes chronic inflammatory and neuropathic pain. Pain 2005; 114: 386-96.

[164] Tsuda M, Kuboyama K, Inoue T, et al. Behavioral phenotypes of mice lacking purinergic $\mathrm{P} 2 \mathrm{X} 4$ receptors in acute and chronic pain assays. Mol Pain 2009; 5: 28.

[165] Xiang Z, Burnstock G. Expression of P2X receptors on rat microglial cells during early development. Glia 2005; 52: 119-26.

[166] Tsuda M, Tozaki-Saitoh H, Masuda T, et al. Lyn tyrosine kinase is required for $\mathrm{P} 2 \mathrm{X}(4)$ receptor upregulation and neuropathic pain after peripheral nerve injury. Glia 2008; 56: 50-58.

[167] Ferrari D, Chiozzi P, Falzoni S, Hanau S, Di Virgilio F. Purinergic modulation of interleukin-1 beta release from microglial cells stimulated with bacterial endotoxin. J Exp Med 1997; 185: 579-82.

[168] Trang T, Beggs S, Wan X, Salter MW. P2X4-receptor-mediated synthesis and release of brain-derived neurotrophic factor in microglia is dependent on calcium and p38-mitogen-activated protein kinase activation. J Neurosci 2009; 29: 3518-28.

[169] Cavaliere F, Dinkel K, Reymann K. Microglia response and P2 receptor participation in oxygen/glucose deprivation-induced cortical damage. Neuroscience 2005; 136: 615-23.

[170] Gong QJ, Li YY, Xin WJ, et al. ATP induces long-term potentiation of C-fiber-evoked field potentials in spinal dorsal horn: the roles of P2X4 receptors and p38 MAPK in microglia. Glia 2009; 57: 583-91.

[171] Sim JA, Park CK, Oh SB, Evans RJ, North RA. P2X1 and P2X4 receptor currents in mouse macrophages. Br J Pharmacol 2007; 152: $1283-90$.

[172] Schilling T, Eder C. Ion channel expression in resting and activated microglia of hippocampal slices from juvenile mice. Brain Res 2007; 1186: 21-28.

[173] Schilling T, Nitsch R, Heinemann U, Haas D, Eder C. Astrocytereleased cytokines induce ramification and outward $\mathrm{K}+$ channel expression in microglia via distinct signalling pathways. Eur J Neurosci $2001 ; 14: 463-73$.

[174] Caggiano AO, Kraig RP. Prostaglandin E2 and 4-aminopyridine prevent the lipopolysaccharide-induced outwardly rectifying potassium current and interleukin-1beta production in cultured rat microglia. J Neurochem 1998; 70: 2357-68.

[175] Chung S, Jung W, Lee MY. Inward and outward rectifying potassium currents set membrane potentials in activated rat microglia. Neurosci Lett 1999; 262: 121-24.

[176] Fischer HG, Eder C, Hadding U, Heinemann U. Cytokinedependent $\mathrm{K}+$ channel profile of microglia at immunologically defined functional states. Neuroscience 1995; 64: 183-91.

[177] Franchini L, Levi G, Visentin S. Inwardly rectifying K+ channels influence $\mathrm{Ca} 2+$ entry due to nucleotide receptor activation in $\mathrm{mi}$ croglia. Cell Calcium 2004; 35: 449-59.

[178] Norenberg W, Gebicke-Haerter PJ, Illes P. Voltage-dependent potassium channels in activated rat microglia. J Physiol 1994; 475: $15-32$.

[179] Schilling T, Quandt FN, Cherny VV, et al. Upregulation of Kv1.3 $\mathrm{K}(+)$ channels in microglia deactivated by TGF-beta. Am J Physiol Cell Physiol 2000; 279: C1123-34.

[180] Schlichter LC, Sakellaropoulos G, Ballyk B, Pennefather PS, Phipps DJ. Properties of $\mathrm{K}+$ and $\mathrm{Cl}$ - channels and their involvement in proliferation of rat microglial cells. Glia 1996; 17: 225-36.

[181] Ilschner S, Nolte C, Kettenmann H. Complement factor C5a and epidermal growth factor trigger the activation of outward potassium currents in cultured murine microglia. Neuroscience 1996; 73: 1109-20.

[182] Norenberg W, Gebicke-Haerter PJ, Illes P. Inflammatory stimuli induce a new $\mathrm{K}+$ outward current in cultured rat microglia. Neurosci Lett 1992; 147: 171-74.

[183] Pyo H, Chung S, Jou I, Gwag B, Joe EH. Expression and function of outward $\mathrm{K}+$ channels induced by lipopolysaccharide in microglia. Mol Cells 1997; 7: 610-14. 
[184] Pannasch U, Farber K, Nolte C, et al. The potassium channels Kv1.5 and Kv1.3 modulate distinct functions of microglia. Mol Cell Neurosci 2006; 33: 401-11.

[185] Norenberg W, Appel K, Bauer J, Gebicke-Haerter PJ, Illes P. Expression of an outwardly rectifying $\mathrm{K}+$ channel in rat microglia cultivated on teflon. Neurosci Lett 1993; 160: 69-72.

[186] Kotecha SA, Schlichter LC. A Kv1.5 to Kv1.3 switch in endogenous hippocampal microglia and a role in proliferation. J Neurosci 1999; 19: 10680-93.

[187] Nutile-McMenemy N, Elfenbein A, Deleo JA. Minocycline decreases in vitro microglial motility, beta1-integrin, and Kv1.3 channel expression. J Neurochem 2007; 103: 2035-46.

[188] Schilling T, Repp H, Richter H, et al. Lysophospholipids induce membrane hyperpolarization in microglia by activation of IKCa1 $\mathrm{Ca}(2+)$-dependent $\mathrm{K}(+)$ channels. Neuroscience 2002; 109: 827-35.

[189] Kaushal V, Koeberle PD, Wang Y, Schlichter LC. The $\mathrm{Ca}^{+}-$ activated $\mathrm{K}^{+}$channel $\mathrm{KCNN} 4 / \mathrm{KCa} 3.1$ contributes to microglia activation and nitric oxide-dependent neurodegeneration. J Neurosci 2007; 27: 234-44.
[190] Khanna R, Roy L, Zhu X, Schlichter LC. K+ channels and the microglial respiratory burst. Am J Physiol Cell Physiol 2001; 280: C796-806.

[191] Woda A. Pain in the trigeminal system: from orofacial nociception to neural network modeling. J Dent Res 2003; 82: 764-8.

[192] Martinez FO, Helming L, Gordon S. Alternative activation of macrophages: an immunologic functional perspective. Annu Rev Immunol 2009; 27: 451-83.

[193] Kohno T, Moore KA, Baba H, Woolf CJ. Peripheral nerve injury alters excitatory synaptic transmission in lamina II of the rat dorsal horn. J Physiol 2003; 548: 131-8.

[194] Lu VB, Biggs JE, Stebbing MJ, et al. BDNF drives the changes in excitatory synaptic transmission in the rat superficial dorsal horn that follow sciatic nerve injury. J Physiol 2009; 587: 1013-32.

[195] Sedlacek M, Horak M, Vyklicky L, Jr. Morphology and physiology of lamina I neurons of the caudal part of the trigeminal nucleus. Neuroscience 2007; 147: 325-33.

[196] Borsook D, Burstein R, Moulton E, Becerra L. Functional imaging of the trigeminal system: applications to migraine pathophysiology. Headache 2006; 46(Suppl 1): S32-38.

(C) Davies et al.; Licensee Bentham Open.

This is an open access article licensed under the terms of the Creative Commons Attribution Non-Commercial License (http://creativecommons.org/licenses/by-nc/3.0/) which permits unrestricted, non-commercial use, distribution and reproduction in any medium, provided the work is properly cited. 